\title{
Assessing the Ecological Impact of Urban Greening: A Case Study of Roadside Planting in Wellington, New Zealand
}

By

Jacob Tessler

A thesis submitted to the Victoria University of Wellington in fulfilment of the requirements for the degree of Master of Science in Ecological Restoration

Victoria University of Wellington 


\section{ABSTRACT}

Roadside reserves in Wellington, New Zealand have been the target of a government-led, community-implemented urban greening initiative for the past 25 years. Prior studies of urban greening have shown numerous benefits to neighbourhoods and communities through increased engagement and stewardship, yet there remains a need for research into the ecological effects these programmes have on individual urban landscapes. This research conducted site surveys to determine the variation in ecological functioning and biodiversity within 36 reserves involved in the Wellington Free Plants Programme (FPP). These measures were compared to historical planting data for each site retrieved from council records. Candidate models were constructed based on novel and classical ecological theory, which sought to explain observed variation between physical and ecological measures across study sites and the relationship between these variables and biodiversity. Sites were small with an area ranging from $5.9 \mathrm{~m}^{2}$ to $246.5 \mathrm{~m}^{2}$ (mean $=37.8 \pm 49.5 \mathrm{~m}^{2}$ ), and biodiversity levels (assessed using a ShannonWeiner Index) ranged from 0.1 to 2.9 (mean $=2.1 \pm 0.7$ ). The top performing candidate models to predict biodiversity included area, shape, and seedbank density. An examination of the effect of varying urban greening efforts across these sites utilised a multivariate analysis which included measures of ecological functioning, biodiversity, the number of years a site had been planted, and the 
number of individual plants provided over those years. A significant negative relationship was found between site disturbance and the number of planting years $\left(F_{33,1}=4.092, p=.051\right)$ while a somewhat significant positive relationship was found between biodiversity and the number of individual plants provided $\left(F_{33,1}\right.$ $=3.536, p=.069)$. These results indicate that current urban greening efforts contribute to the ecological health of roadside reserves and that the patterns and processes governing the biological composition of these reserves may be partially explained with traditional ecological theory. 


\section{ACKNOWLEDGEMENTS}

This research was made possible through the access of planting records granted by the Wellington City Council. Many thanks to the staff at the Berhampore Nursery for their assistance in providing data as well as their dedication to ecological restoration.

I would also like to thank my thesis supervisor Dr Wayne Linklater for providing guidance and feedback during the course of this research.

Finally, thank you to all my family, especially my partner Whitney for her limitless support and patience. 


\section{TABLE OF CONTENTS}

$\begin{array}{lc}\text { Abstract } & \text { ii } \\ \text { Acknowledgements } & \text { iv } \\ \text { Table of Contents } & \mathrm{v} \\ \text { List of Figures } & \mathrm{vi} \\ \text { List of Tables } & \mathrm{vii}\end{array}$

$\begin{array}{ll}\text { Chapter } 1 \text { - Introduction } & 1\end{array}$

Chapter 2 - The relationship between physical factors, ecological functions and biodiversity in small urban patches.

$\begin{array}{ll}\text { Introduction } & 10\end{array}$

$\begin{array}{ll}\text { Methods } & 13\end{array}$

$\begin{array}{ll}\text { Results } & 19\end{array}$

$\begin{array}{ll}\text { Discussion } & 30\end{array}$

Chapter 3 - The ecological effects of community planting over a 25 year period in Wellington, New Zealand.

Introduction 36

$\begin{array}{ll}\text { Methods } & 39\end{array}$

$\begin{array}{ll}\text { Results } & 41\end{array}$

$\begin{array}{ll}\text { Discussion } & 47\end{array}$

Chapter 4-Conclusions $\quad 52$

References $\quad 55$

Appendix I: Location of study sites across Wellington 64 


\section{LIST OF FIGURES}

Figure 1: Frequency distributions of area, slope, shape, and deprivation index at surveyed sites

Figure 2: Frequency distributions for decomposition (bag weight), disturbance, diversity index, and seedbank density at surveyed sites

Figure 3: $\quad$ Site diversity as a function of area within each of the 36 sites surveyed

Figure 4: $\quad$ Site diversity as a function of site shape within each of the 36 sites surveyed

Figure 5: $\quad$ Site diversity as a function of seedbank density (number of seeds per $42.41 \mathrm{~cm}^{3}$ ) at each of the 36 sites surveyed

Figure 6: $\quad$ Frequency distribution for the number of planted individuals

Figure 7: $\quad$ Frequency distribution for the number of planting years

Figure 8: $\quad$ Four ecological factors as a function of the number of individuals planted at each study site over a 25 year period

Figure 9: The average measure of four ecological factors as a function of the number of years a given site was planted 


\section{LIST OF TABLES}

Table 1: $\quad$ Site characters surveyed and sourced

Table 2: $\quad$ Candidate models for factors affecting site biodiversity

Table 3: $\quad$ Summary statistics for physical/social factors surveyed

Table 4: $\quad$ Correlation matrix for physical/social factors surveyed

Table 5: $\quad$ Summary statistics for ecological factors surveyed

Table 6: $\quad$ Correlation matrix for ecological factors surveyed

Table 7: $\quad$ Explanatory models describing site biodiversity

Table 8: $\quad$ Historical site variables surveyed

Table 9: $\quad$ Summary statistics for historical site variables surveyed 


\section{Chapter 1}

\section{INTRODUCTION}

The field of urban ecology has undergone a paradigm shift in recent years, as cities are increasingly seen as a part of ecosystems instead of as altered landscapes in which ecosystems persist (Alberti et al. 2003). In addition to naturally occurring greenspace, built areas within cities may contribute to, and themselves constitute, broadly defined habitat. Moving towards a consideration of the ecology of cities as opposed to the ecology in cities is forming a cornerstone of modern urban ecology (McDonnell et al. 2009). This dichotomy consists of two distinct ecological approaches: "ecology of cities" is a more inclusive approach which seeks to characterise individual cities as functioning ecosystems, while "ecology in cities" targets all non-human biological components (Grimm et al. 2000; Niemela et al. 2009; Wu 2008)

Ecology of cities builds upon ecology in cities, and has moved from a nested subset into a distinct field of ecological enquiry (Niemela et al. 2009). Niemela et al. (2009) attribute much of this progression to the abandonment of traditional ecological equilibrium theory in which ecosystems are assumed to be the healthiest when in balance. The view of urban systems as heavily disturbed is “...giving way to dynamism and the recognition that systems are often not in 
equilibrium." (Niemela et al. 2009, p.12). The multi-disciplinary framework required for a socio-inclusive "ecology of cities" approach is likely to be more resource intensive and may explain why progress has been comparatively slow (McDonnell et al. 2009).

Although urban areas vary in terms of size and intensification, studies have shown consistency between cities in regards to carbon sequestration and the availability of limiting nutrients, indicative of successful ecological functioning (Nowak \& Crane 2002; Pickett et al. 2011). Still, it is believed that these ecosystems cannot fully replicate the level of functionality found in their 'natural' counterparts (Kowarik 2011). While there has been a marked expansion in urban field research over the last decade, there remains a great need for research surrounding species interactions, functional dynamics, and the ecological processes that contribute to urban environments (Heneghan et al. 2009).

In cities, high levels of environmental disturbance combine with high availability of resources (either by conventional proximity to humans or imported for use), which influence species assemblage (Turner 1989; McKinney 2006). This often results in an abundance of urban-adapted generalists that can displace local biota with more specific resource requirements (Shochat et al. 2006). New Zealand's urban centres are distinct from their counterparts in Europe, North America, and Australia in the disproportionate level of exotic species that dominate their ecosystems (Freeman \& Buck 2003). Widespread urbanisation and the threat this poses to locally-adapted native species, makes research on urban 
ecosystems in a New Zealand context particularly urgent. While the novelty of urban environments makes the application of classic ecological theory difficult, it does, however, allow for the development and testing of novel ecological functions in a unique 'socio-ecological' system. (Grimm et al. 2008; Gaston et al. 2010).

Biotic and abiotic processes in urban environments differ from environments with less direct anthropogenic influence, and as such, restoration efforts are being increasingly viewed with humans as the main source of process manipulation (Burke \& Mitchell 2007). For instance, human activities can lead to increased temperatures, which may alter season patterns and effect species migrations and breeding (Shochat et al. 2006). It is difficult to minimise human influence on an urban environment, however some cities have made attempts to channel involvement towards positive ecological outcomes. For instance, the Wellington City Council operates a Free Plants Programme (FPP), providing native plants to residents for planting on roadside sites. Such initiatives may be the key to enhancing urban habitat and resource availability, which has been shown to increase arthropod communities, plant productivity, and contribute significantly to overall ecological health (Muller et al. 2014).

Roadside sites are a common characteristic of modern urbanisation and represent an interesting junction between the processes of natural succession and artificially high levels of disturbance. Often found on public lands, these sites are removed from the usual difficulties that surround experimental designs in urban 
ecology. Parks, gardens, and reserves represent moderate levels of urbanisation and, holding with the intermediate-disturbance hypothesis (Connell 1978) and resource availability, should exhibit relatively high indices of species richness. These sites are often the focus of local restoration projects and, despite their size, can have a significant impact on the city's ecosystem: small restoration sites $(<500 \mathrm{~m} 2)$ have already been shown to act as valuable seed sources in New Zealand's most urbanised areas (Sullivan et al. 2009). This is especially important as recent studies have shown local seed banks and seed source availability to be limitation factors in urban succession (Albrecht et al. 2011; Overdyck \& Clarkson 2012). Additionally, Viles and Rosier (2001) found that roadside greenways represent an opportunity to increase connectivity, biodiversity, and overall ecological health in New Zealand, by targeting disused land and mitigating the localised and detrimental ecological effects of passing vehicles (e.g. pollution and invasion vectors).

As such, the importance of quantifying the ecological functioning of these roadside reserves and their contribution to the urban landscape should not be understated. Whether the functioning of roadside reserves is a reflection of a larger ecological apparatus or a component thereof should be a question posed by ecologists, city planners, and stakeholders alike.

Urban ecology research has typically been observational in nature, due in large part to difficulties associated with property rights, human interference and most importantly, the high variability in spatial landscapes (Gaston 2010). 
However, community-based restoration efforts like the Wellington City Council's FPP, which seeks to turn urban wastelands (disused sites with spontaneous vegetation) into purposefully planted roadside reserves, provide a unique opportunity to put existing observational methodologies into an experimental design.

Local-scale factors (both ecological and managerial) are suggested to play a more significant role predicting and enhancing biodiversity in urban environments than those of a larger landscape-scale (Schwartz et al. 2013). Examples of commonly studies ecological factors include decomposition rates, disturbance, and seedbank characteristics. Relative measures of these site characteristics can provide a better understanding of the long-term, ecological benefits associated with small-scale urban restoration projects. When considered in terms of volunteer community actions, this type of analysis may help to determine whether any ecological value is contributed by programmes with known social benefits. This will help inform future implementation and management of community-based restoration strategies.

Growing pressure placed on global ecology as a product of anthropogenic expansion will be best served by a compendium of "international, comparative work on...management systems of urban green space" (Niemela 2014, p. 299), including an assessment and monitoring scheme.

This study seeks to examine sites with similar land-use qualities (i.e. road reserves) in regards to ecological variation as well as whether any of this variation 
can be explained as a function of treatment over time. Ecological studies in urban environments often focus on one of several themes, including changing land-use analysis, 'natural' plot comparisons, and numerous gradient analyses (Gaston 2010; McDonnell et al. 2009; Pickett et al. 2011). Combining aspects of what is has been traditionally considered separate avenues of ecological study will hopefully provide valuable insight into the interplay between ecological health and government and community involvement and the relationship between these elements as a function of time.

Urban ecology research often focuses on broad aggregations of variables (i.e. patch distance from industrial/commercial centres and land-conversion factors like impermeable surface cover and vegetation loss (McDonnell \& Hahs 2013). Though there is value to broad-scale pattern analysis, there is a growing need to investigate the underlying mechanisms and processes within established urban matrix frameworks. This has been done with varying degrees of success in recent years (Bonnington et al. 2013; Williams \& Winfree 2013), yet the variation in urban intensity and landscape across the world's cities calls for the wider application of city-specific research to characterise novel ecological processes (Ramalho \& Hobbs 2012). Moving from large-scale analysis to a finer, habitat-level scale is difficult as patterns break down and individual patch dynamics become more prominent drivers of ecosystem composition and function (Kowarik et al. 2011). Therefore, urban ecosystems are better defined as complex mosaics which may require an examination of the smaller, individual patches that comprise the 
urban landscape. By using a localised approach, it is possible to shine light on underlying ecological processes that may have widespread application.

Cites often exhibit higher levels of species richness than neighbouring, rural areas, as well as supporting rare and endangered species (Alvey 2006). For example, Christchurch, New Zealand is a city surrounding by pastoral lands, and, as such, maintains a higher plant diversity than its regional surroundings (Stewart et al. 2004). The relationship between increased diversity and ecological stability has been debated for decades and, at its best possibly, can been considered an oversimplification of system complexities (McNaughton 1977; Tilman 1996).

In 2014, Bonthoux et al. found that urban wasteland sites in Western and Central Europe supported greater species richness and diversity than similarly sized, intentional green spaces, leading to the recommendation that future management plans prioritise the protection and inclusion of wasteland in conservation efforts. The Wellington region FPP has been working within a similar framework over recent years by providing locally-sourced plants to residents interested in creating novel green space along local public wastelands (roadside reserves). The expressed goals of the programme are to enhance ecosystem services and functions by promoting clean water, regulating runoff, storing carbon, increasing native plant populations, and providing diverse habitat for native birds, lizards, and insects, yet most of these lack evidentiary support and have been poorly explored in urban settings (Pataki et al. 2011). 
While variation in species diversity across the urban gradient has been the focus of numerous studies there is significantly less literature devoted to how patterns change as a function of time (Luck \& Smallbone 2010). This is unsurprising given the added logistic and resource requirements of long-term ecological monitoring. Programmes like the FPP provide and excellent framework for post hoc investigations; changes in programme goals and implementation, such as the removal of most exotic species from plant offerings, can provide an excellent opportunity for broad, temporal analysis. There is substantial research addressing the human benefits to community-based urban greening efforts ranging from psychological and social (Sommer et al. 1994; Armstrong 2000) to reductions in neighbourhood crime rates (Westphal 2003). The ecological benefits, however, resist broad theoretical approaches due to localised system complexity and need to be examined on an individual initiative and city basis (Hostetler et al. 2011).

This research recognises the need for an evaluation of small-scale urban ecological systems, with a focus on comparative functioning and the associated restoration value of community-based efforts, the long-term environmental outcomes of which have been poorly studied (Peters et al. 2015). It is expected that the study sites are likely to be representative of heavy fragmentation due to their proximity to highly urbanised landforms (i.e. roads), and as such, may exhibit a reduction in their functional potential. A healthy ecosystem is dependent upon not only internal species interactions, but numerous abiotic factors and ecological functions which are inextricably linked to species diversity (Meyer 1997). The 
relationship between biodiversity and ecological functioning in small, urban greenspace is still poorly understood and requires greater research attention (Schwartz et al. 2013).

Although the active planting of native species may result in an increase in species-specific connectivity, the additional stressors associated with active human involvement (e.g. disturbance, exotic introductions, etc.) may not warrant these types of actions. Indigeneity of plantings (at least at the individual level) within the FPP planted sites is positively correlated with survival rates (Berentson 2013), but the degree to which the forced assemblage of native plant species contributes to overall biodiversity and ecosystem function is not known. Similarly, community group access and habitat manipulation at these sites may lead to an increase in measurable disturbance, or altered decay rates and soil seed bank availability. Through an examination of these measures this thesis seeks to explore the relationships between ecological functioning and biodiversity within small-scale urban bush sites and any benefits conferred through increased community planting efforts. 


\section{Chapter 2}

\section{THE RELATIONSHIP BETWEEN PHYSICAL FACTORS, ECOLOGICAL FUNCTIONS AND BIODIVERSITY IN SMALL URBAN PATCHES.}

\section{INTRODUCTION}

The vegetative structure of urban greenspaces, like all ecosystems, is governed by the complex interactions of a variety of processes (McDonnell et al. 2009). In natural environments, the interplay between disturbance, decomposition, and biodiversity are well documented across both habitat and landscape scales (Attiwill 1994; Hooper et al. 2005). In urban environments, habitat patterns across landscapes (i.e. rural-urban gradient analyses) are similarly well documented, but small-scale processes are less well-known (McDonnell \& Hahs 2008; Ramahlo \& Hobbs 2012).

Ecosystem health is reflected in the consistency of processes and functions which are considered normal given the size, shape and historical context of a given site (Tzoulas et al. 2007). These processes and functions can only be judged for efficiency and normalcy given locally specific baselines to determine relevant changes as sites are exposed to the outside processes of surrounding landscape. Using decomposition, disturbance, and soils seed banks to characterise ecological function allows for research into the current and projected ecological health of 
urban landscapes. When combined with site-specific biodiversity, these measures can help inform the dynamics that are fundamental to understanding an urban ecological system.

Biodiversity becomes an increasingly important factor in ecosystem function as the urbanisation of an area increases (Alberti 2008). Studies examining green space within the urban matrix have shown that diversity is often greater in areas where vegetation more closely approximates pre-urbanisation land cover (Koh \& Sodhi 2004). Decomposability in an urban environment is widely variable and largely governed by the local physical and biological environment (Carreiro et al. 1999). At smaller scales, decay rates are determined by a combination of the chemical composition of leaf litter, biodiversity, and microclimates, contrasting with larger scales where climate has been found to be the largest predictor variable (Turner 1989). Disturbance in urban areas is well researched and presents in many forms, yet is commonly observed through the introduction of biogeographic barriers (i.e. roads, buildings, parking lots) which can increase habitat fragmentation and alter landscape connectivity (Alberti 2008).

Urban soils are generally characterised as of a poor quality, with reduced nutrient availability, high $\mathrm{pH}$ and high heavy metal pollution (Craul 1992). However, Pickett et al. (2008) found evidence in two major North American cities that urban soils may vary significantly in quality across the urban landscape. The highly variable nature of soils across the urban landscape necessitates an understanding of specific seed traits and abundance which have been shown to be 
critical for successful recruitment and seedling establishment in urban forest restoration (Overdyck \& Clarkson 2012).

Although site area has long been a more widely considered predictor of ecological organisation and function than that of site perimeter, research has become more inclusive of the latter (Horak 2016). Both area and perimeter are included in the preliminary analysis of this chapter and any statistical difficulties that may arise as a result of modelling collinearity will be addressed and discussed.

Socio-economic factors have been shown to be positively correlated with increased species richness is plants (Hope et al. 2003; Martin et al. 2004). To incorporate a socio-economic component this research utilised deprivation information available from the New Zealand Deprivation Score, an index categorising mesh block areas based on multiple socio-economic variables (Atkinson et al. 2014).

The aim of this chapter is to assess variation in the physical characters and ecological functioning of 36 roadside reserves that have been planted as part of the FPP and determine what relationship if any, this variation has with biodiversity. The primary questions being explored are as follows:

1) How do small-scale urban bush sites function in comparison to each other?

2) Does variation in ecological functioning effect local biodiversity?

It is expected that site-specific biodiversity will correlate with higher rates of decomposition as increased biodiversity can lead to greater variation in the 
chemical composition of detritus and leaf litter. This is expected to result in higher decomposition efficiency, which will be largely regulated by local biotic factors (abiotic factors are not expected to vary significantly between sites). Biodiversity across sites is expected to decrease as a function of disturbance. Although increased site disturbance may limit recruitment in certain species and decrease the potential biomass through seedling establishment reduction (e.g. trampling), it is likely any observed relationship will have a weak correlation to both biodiversity and decomposition across all sites.

\section{METHODS}

\section{Site Selection}

Sites were selected from archived planting data provided by the Wellington City Council as part of the FPP. 150 randomly selected sites were culled down to 36 based on the following criteria: site is found on public land, site represents reasonably safe working conditions, there exists a strong likelihood that the site selected has been planted in conjunction with the FPP (archival records were limited to the address of recipient and brief descriptions of proposed planting site). Site locations can be found in Appendix I.

\section{Site Characters}


Study methods for the 3 measures of ecological function investigated in this thesis are expanded upon below. The full list of site characters included in analysis can be found in Table 1.

Decomposition analysis utilised Lipton ${ }^{\circledR}$ pyramid tea bags to determine decay rates, providing standardised bag weight, composition and mesh size. 6 tea bags were buried $8 \mathrm{~cm}$ deep in a random array at each of the sites and retrieved 90 days later. Bags were cleaned of loose debris and roots, dried at a constant temperature of $20^{\circ} \mathrm{C}$ for 48 hours, and weighed. This value was compared to an average pre-burial weight ( $1.94 \mathrm{~g})$ determined through a random sampling of 15 bags given similar drying treatment. Due to logistic difficulties in the retrieval of all 6 bags from each site (bag locations were discreetly, but visibly marked and there were multiple incidents of missing bags on subsequent site visits) the original experimental design of repeated measures over time was abandoned for a single survey of any remaining bags. While this does not allow for insight into changing decomposition rates over time as a function of available temperature and rainfall data, it will provide a comparative measure of decay for analysis. However, due to the varying number of bags retrieved per site (1-6) it was decided to only include the bag with the lowest weight (highest decomposition) in analysis.

Seed bank character was intended to be assessed with emergence and extractive measures to provide both density and viability estimations (Abella et al. 2013). 3 soil core samples $(3 \mathrm{~cm} \times 0-6 \mathrm{~cm})$ were taken from each site, washed using a 150um mesh sleeve, and hand sorted using US Standard \#35 sieve (500um). Due 
to the high frequency of low and zero values recorded, the final analysis will consist solely of the core exhibiting the highest density of seeds. As all core samples were randomly placed, the seed density value can be interpreted as an optimal representation of recruitment potential. Seeds were then sprouted over 45 days. However, due to low a low incidence of emergence within the prescribed timeframe and logistical constraints preventing the extension of said timeframe this aspect of the seedbank measure was not included in the final analysis.

Site biodiversity was assessed visually with vegetative counts and was largely limited to woody species. Where sites were thoroughly accessible and relatively small $\left(<10 \mathrm{~m}^{3}\right)$ full vegetative counts were conducted. At larger sites $\left(>10 \mathrm{~m}^{3}\right)$ or those sites where through access was impossible (dense or hazardous conditions) transects were established with $1 \mathrm{~m}$ quadrats placed every $5 \mathrm{~m}$. Species level identification along with number of individuals present was recorded.

Disturbance is widely regarded as a significant driver of ecological assemblage and functioning (Attiwill 1994). The difficulty in qualifying and quantifying disturbance in ecological research is apparent in both temporal and logistic approaches. Due to the inaccessible and steep nature of many of my study sites it was decided to limit disturbance measures to erosion, slips, and other visibly evident disturbances along the edges of the study sites. It was hypothesized that much of the internal site disturbance found would be a result of intentional and unintentional human disturbance as a result of the planting scheme to which these sites are or have been subjected. It is hoped that much of this variation will be explained through differences in planting intensity across 
sites, the examination of which will form the bulk of the analysis in Chapter 3.

Disturbance was determined through a visual assessment of site edges (due to site proximity to public access and roadways, as well as steep slopes, the majority of expected disturbance was assumed to be in relation to vegetative trimming/edging, mowing, and bank slippage). Disturbance was measured as a percentage of the total accessible site edge.

All field work was conducted October-January 2017.

\section{Statistical Methods}

A model selection approach was chosen due to the observational nature of much of the collected data and the assumed complexity of the ecological systems in question. This approach enables multiple hypothesis testing and is ideal for post hoc analysis when conducting research within the confines of non-experimentally designed scenarios (Johnson \& Omland 2004). Candidate models were developed based on the proposed explanatory power of variables and variable interactions

(Table 2). These models were compared utilising an information-theoretic approach where ranking was establishing based on Akaike Information Criterion (AIC). The small sample size of the study was corrected for using second order AICs and ultimately weighted to establish a given model being the best fit within the candidate set (Burham \& Anderson 2002). 
Table 1

\section{Site characters surveyed}

\begin{tabular}{llll}
\hline Variable(s) & Category & Measure & Method \\
\hline Area; Perimeter & Physical & $\mathrm{m}^{2} ; \mathrm{m}$ & Site boundaries mapped with GPS area and perimeter calculated in GIS \\
Slope & Physical & degrees & Measured using clinometer \\
Aspect & Physical & degrees from north & Measured using compass \\
Shape & Physical & ratio & perimeter/area \\
Deprivation Index & Socioeconomic & rank & Retrieved from existing data * \\
Disturbance & Ecological & $\%$ & Explained in text \\
Decomposition & Ecological & $\mathrm{g}$ & Explained in text \\
Seedbank Density & Ecological & highest sampled value & Explained in text \\
Biodiversity & Ecological & Shannon-Weiner Index & Explained in text \\
\hline *Atkinson et al. 2014 & & &
\end{tabular}


Table 2

Candidate models for factors affecting site biodiversity

Variable(s) $\quad$ Reference(s)

Seedbank

Albrecht et al. 2011; Overdyck \& Clarkson 2012

Decomposition

Sayer 2006; Hattenschwiler et al. 2005

Disturbance

Attiwill 1994

Area

Cornelis \& Hermy 2004

Slope

Chapin et al. 2011

Shape

Helzer \& Jelinski 1999

Degrees from North

Chapin et al. 2011

Deprivation Index

Iverson \& Cook 2000

Area $\times$ Shape

Perimeter + Slope

Degrees from North + Slope

Chapin et al. 2011

Seedbank x Perimeter

Seedbank + Disturbance

Eriksson \& Eriksson 1997

Seedbank + Decomposition

+ Disturbance 


\section{RESULTS}

Descriptive Statistics

Physical factors measured at each site varies widely (Table 3). The surveyed area of sites showed $63.9 \%$ were considered small in size $\left(>25 \mathrm{~m}^{2}\right)$ while only 2 sites were moderate-to-large $\left(>150 \mathrm{~m}^{2}\right)$. The median slope for surveyed sites was 19.2 degrees and considered moderate while $27.8 \%$ of surveyed sites had a slope that was considered steep (>25\%). Site shape (perimeter-area ratio) ranged from 0.4 to 4.8 with a median ratio of 1.9 . $75 \%$ of sites were found to have a ratio of $<2.5$, with $44.4 \%$ of those sites exhibiting a ratio of between 1.5 and 2 (Figure 1 ). Sites with a higher ratio value were found to be less regular in shape than sites with a lower ratio value.

The lone social factor included in this study, deprivation index, was found to vary widely across sites, ranging from a score of 1 to 9 (out of a possible 10) with a median score of 4 . Although $27.8 \%$ of sites had a middle score of 5 indicating neither association with affluence or poverty, $55.6 \%$ of sites were scored $>5$ indicating that these sites were located within relatively affluent neighbourhoods (Figure 1). All physical/social factors were assessed for collinearity with a significant relationship found between area and perimeter $(p<0.01)$ (Table 4). 
Table 3

Summary statistics for physical/social factors surveyed

\begin{tabular}{lcccccc}
\hline & Area & Perimeter & Slope & Degrees from North & Deprivation Index & Shape \\
\hline Mean & 37.8 & 56.4 & 20.4 & 172.7 & 4.2 & 2.2 \\
Standard Error & 8.3 & 6.7 & 2.2 & 18.0 & 0.3 & 0.2 \\
Median & 20.5 & 42.1 & 19.2 & 151.5 & 4.0 & 1.9 \\
Standard Deviation & 49.5 & 39.9 & 13.2 & 107.7 & 2.0 & 1.0 \\
Skewness & 3.1 & 2.6 & 0.9 & 0.2 & 0.7 & 1.0 \\
Range & 240.6 & 210.6 & 53.6 & 331.0 & 8.0 & 4.4 \\
Minimum & 5.9 & 9.8 & 2.1 & 21.0 & & 0.0 \\
Maximum & 246.5 & 220.4 & 55.7 & 35.0 & 9.0 & 4.8 \\
\hline
\end{tabular}


Table 4

Correlation matrix for physical/social factors surveyed

\begin{tabular}{lccccc}
\hline & Area & Perimeter & Slope & Degrees from North & Deprivation Index \\
\hline Area & - & $0.824^{*}$ & 0.036 & 0.075 & 0.245 \\
Perimeter & 0.000 & - & 0.025 & 0.137 & 0.111 \\
Slope & 0.835 & 0.885 & - & 0.055 & 0.265 \\
Degrees from North & 0.664 & 0.426 & 0.749 & - & -0.200 \\
Deprivation Index & 0.150 & 0.519 & 0.118 & 0.243 & - \\
\hline
\end{tabular}

Note - correlation coefficients are presented in the top tier while $p$-values are presented in the bottom tier.

*Correlation is significant at the 0.01 level (2-tailed) 

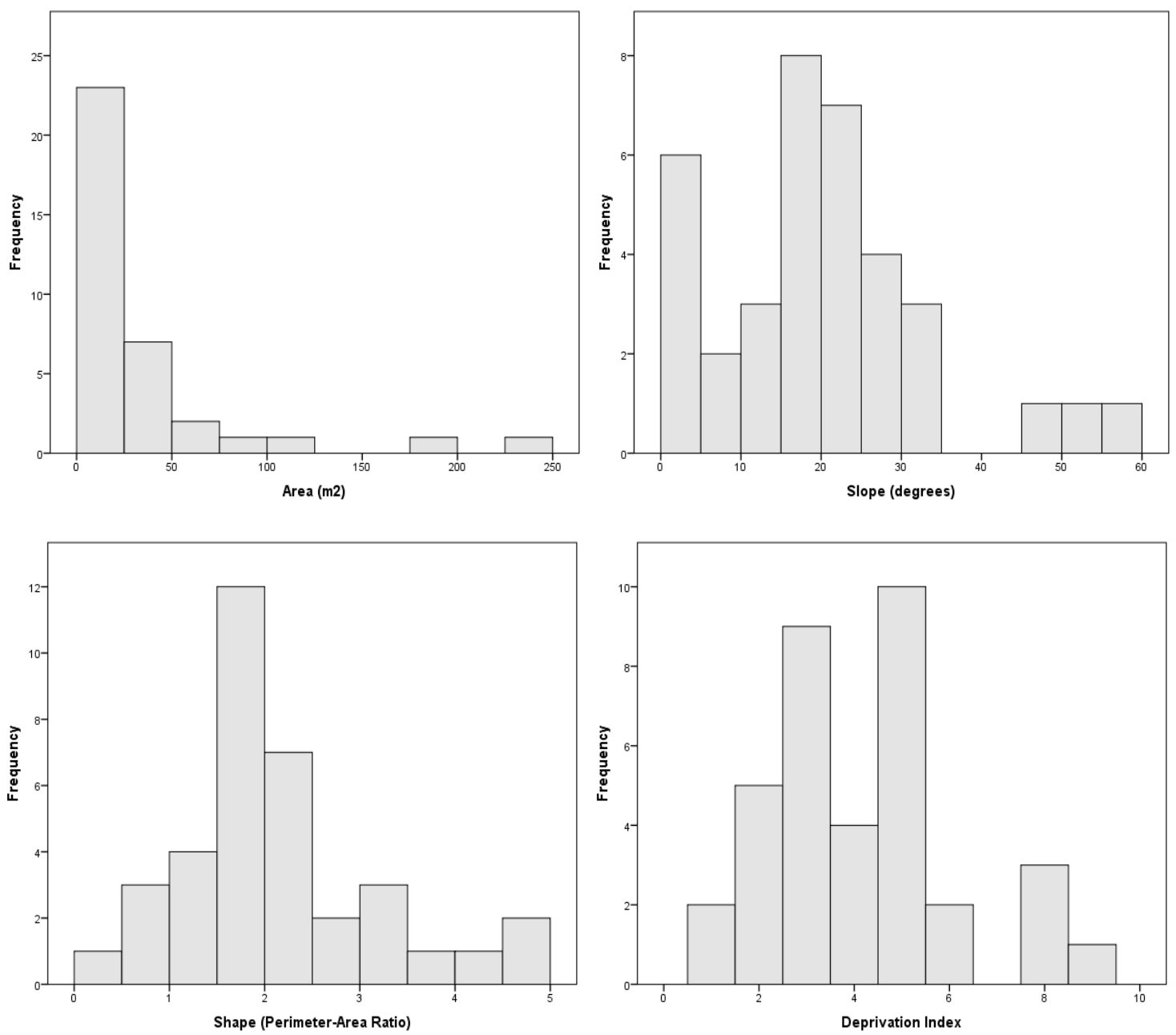

Figure 1. Frequency distribution of area, slope, shape, and deprivation index at surveyed sites.

Ecological factors measured at each site varied widely (Table 5). The variation found in decomposition was especially pronounced with final bag weights ranging from $0.2 \mathrm{~g}$ to $1.9 \mathrm{~g}$ with $63.9 \%$ of sites presenting a final bag weight between $1.0 \mathrm{~g}$ and $1.5 \mathrm{~g}$. Median disturbance across sites was $20 \%$ with $72.2 \%$ of sites exhibiting low levels of disturbance $(<30 \%)$. Only 1 site was considered heavily disturbed (>80\%). Biodiversity levels were generally high with $66.6 \%$ of 
sites maintaining an index score of 2.0 or higher, $37.5 \%$ of which were between 2.5 and 3.0. Seedbank densities were considerably lower than expected with seed numbers ranging between 3 and 34 individual seeds. $27.7 \%$ of cores sampled were found to have more than 20 seeds per $42.41 \mathrm{~cm}^{3}$ (Figure 2). These variables were assessed for collinearity with no significant relationships found (Table 6). 
Table 5

Summary statistics for ecological factors surveyed

\begin{tabular}{lcccc}
\hline & Seedbank Density (\#) & Decomposition (g) & Disturbance (\%) & Diversity Index \\
\hline Mean & 16.9 & 1.3 & 23.5 & 2.1 \\
Standard Error & 1.4 & 0.1 & 2.7 & 0.1 \\
Median & 14.5 & 1.3 & 20.0 & 2.1 \\
Standard Deviation & 8.4 & 0.3 & 16.1 & -1.4 \\
Skewness & 0.7 & -1.3 & 1.8 & 2.8 \\
Range & 31.0 & 1.7 & 72.5 & 0.1 \\
Minimum & 3.0 & 0.2 & 7.5 & 2.9 \\
Maximum & 34.0 & 1.9 & 80.0 & \\
\hline
\end{tabular}


Table 6

Correlation matrix for ecological factors surveyed

\begin{tabular}{lccc}
\hline & Seedbank & Decomposition & Disturbance \\
\hline Seedbank & - & -0.174 & -0.122 \\
Decomposition & 0.311 & - & 0.030 \\
Disturbance & 0.478 & 0.860 & - \\
\hline
\end{tabular}

Note - correlation coefficients are presented in the top tier while p-values are presented in the bottom tier.
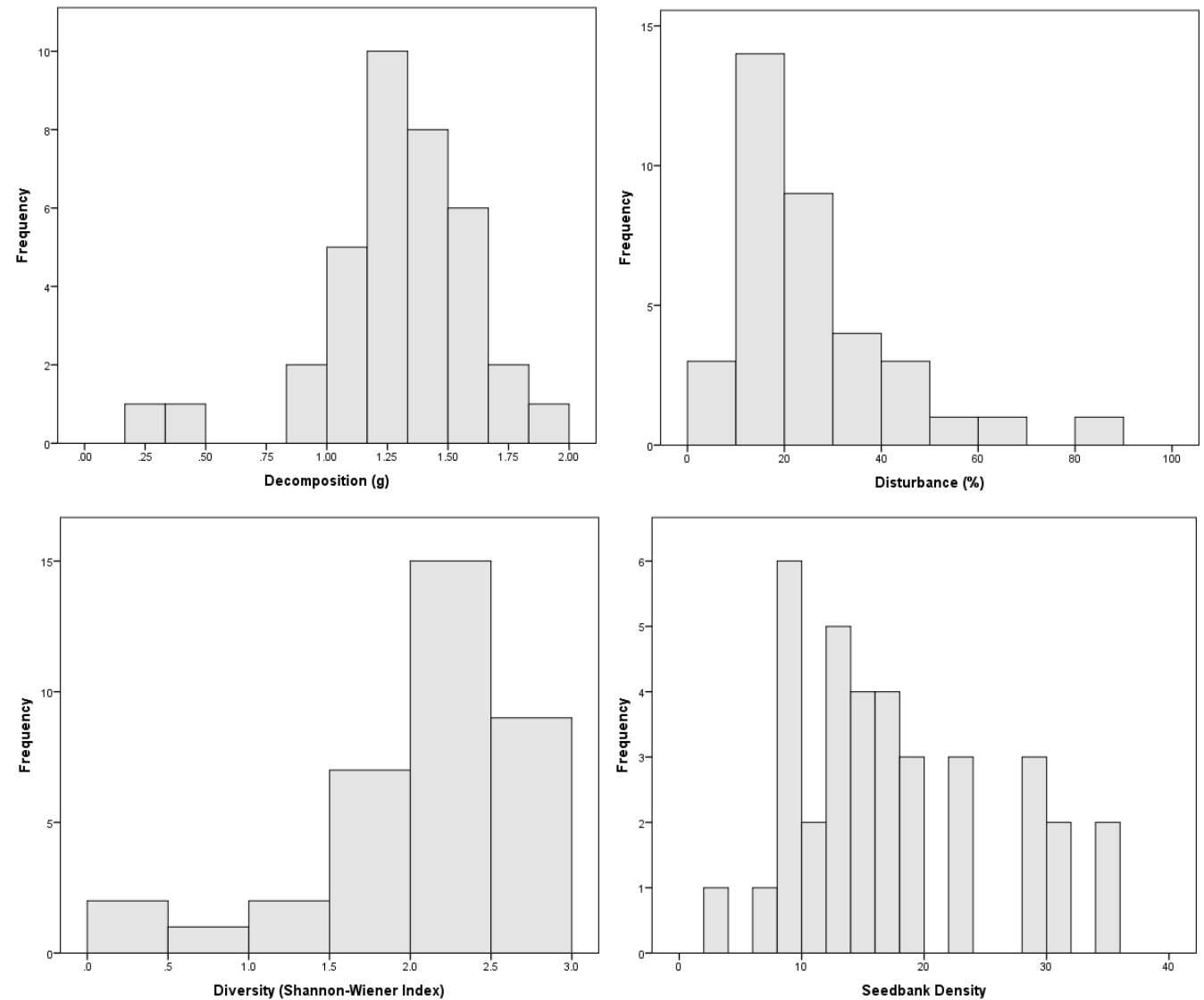

Figure 2. Frequency distributions for decomposition (final bag weight), disturbance,

diversity index, and seedbank density at surveyed sites. 
Model Selection

Although site perimeter was included in preliminary analysis, initial correlation assessment suggested that measures of perimeter and area were indeed linked. To avoid any statistical bias in the modelling associated with multicollinearity (Graham 2003), perimeter was not included in final model selection.

Fixed-effects models are presented in descending order according to their AIC weights (wi) in Table 7. A 95\% confidence set includes models $1-12$ (sum of AIC weights $=0.9677)$. This set excludes Model 13 (Degrees from North + Slope) and Model 14 (Seedbank + Decomposition+ Disturbance), although as all models were within $10 \triangle \mathrm{AIC}$ of each other none can be omitted as lacking any explanatory power. 
Table 7

Explanatory models describing site biodiversity

\begin{tabular}{|c|c|c|c|c|c|c|}
\hline & Model & k & AIC & $\operatorname{AICc}(n=36)$ & $\triangle \mathrm{AIC}$ & wi \\
\hline 1 & Area & 3 & -37.103 & -36.353 & 0 & 0.2774 \\
\hline 2 & Site Shape & 3 & -35.574 & -34.824 & 1.529 & 0.1291 \\
\hline 3 & Seedbank & 3 & -35.345 & -34.595 & 1.758 & 0.1152 \\
\hline 4 & Deprivation Index & 3 & -34.910 & -34.160 & 2.193 & 0.0927 \\
\hline 5 & Degrees from North & 3 & -34.578 & -33.828 & 2.525 & 0.0785 \\
\hline 6 & Seedbank * Perimeter & 5 & -35.028 & -33.028 & 3.325 & 0.0526 \\
\hline 7 & Disturbance & 3 & -33.348 & -32.598 & 3.755 & 0.0424 \\
\hline 8 & Slope & 3 & -33.341 & -32.591 & 3.762 & 0.0423 \\
\hline 9 & Decomposition & 3 & -33.339 & -32.589 & 3.764 & 0.0422 \\
\hline 10 & Seedbank + Disturbance & 4 & -33.583 & -32.293 & 4.060 & 0.0364 \\
\hline 11 & Perimeter + Slope & 4 & -33.357 & -32.067 & 4.286 & 0.0325 \\
\hline 12 & Shape * Area & 5 & -33.640 & -31.640 & 4.713 & 0.0263 \\
\hline 13 & Degrees from North + Slope & 4 & -32.625 & -31.335 & 5.018 & 0.0226 \\
\hline 14 & Seedbank + Decomposition & 5 & -31.663 & -29.663 & 6.690 & 0.0098 \\
\hline & + Disturbance & & & & & \\
\hline
\end{tabular}


Three single-factor models performed best based on AIC analysis of the candidate set. Although Area was ranked the highest $(\mathrm{AICC}=-37.103, \mathrm{wi}=0.2774)$, Seedbank and Shape are within $2 \triangle \mathrm{AIC}$ and are therefore considered indistiguishable within the modelling confines (Burnham \& Anderson 2002). Area was shown to have a weak positive relationship with site biodiversity $\left(R^{2}=0.080\right)$. Although the majority of sites were small in size $\left(>50 \mathrm{~m}^{2}\right)$ these sites represented the full range of diversity levels found $(0.092-2.88)$ (Figure 3). Both sites with an area over $150 \mathrm{~m}^{2}$ were found to have a diversity index over 2.5 . The shape ratio of sites was found to have a weak negative relationship with biodiversity $\left(R^{2}=0.061\right)$. No sites with a perimter-area ratio greater than 3.5 were found to have a diversity index over the mean for all sites (2.056) (Figure 4). Seedbank was found to have a weak positive relationship with site diversity $\left(R^{2}=0.055\right)$ (Figure 5). 


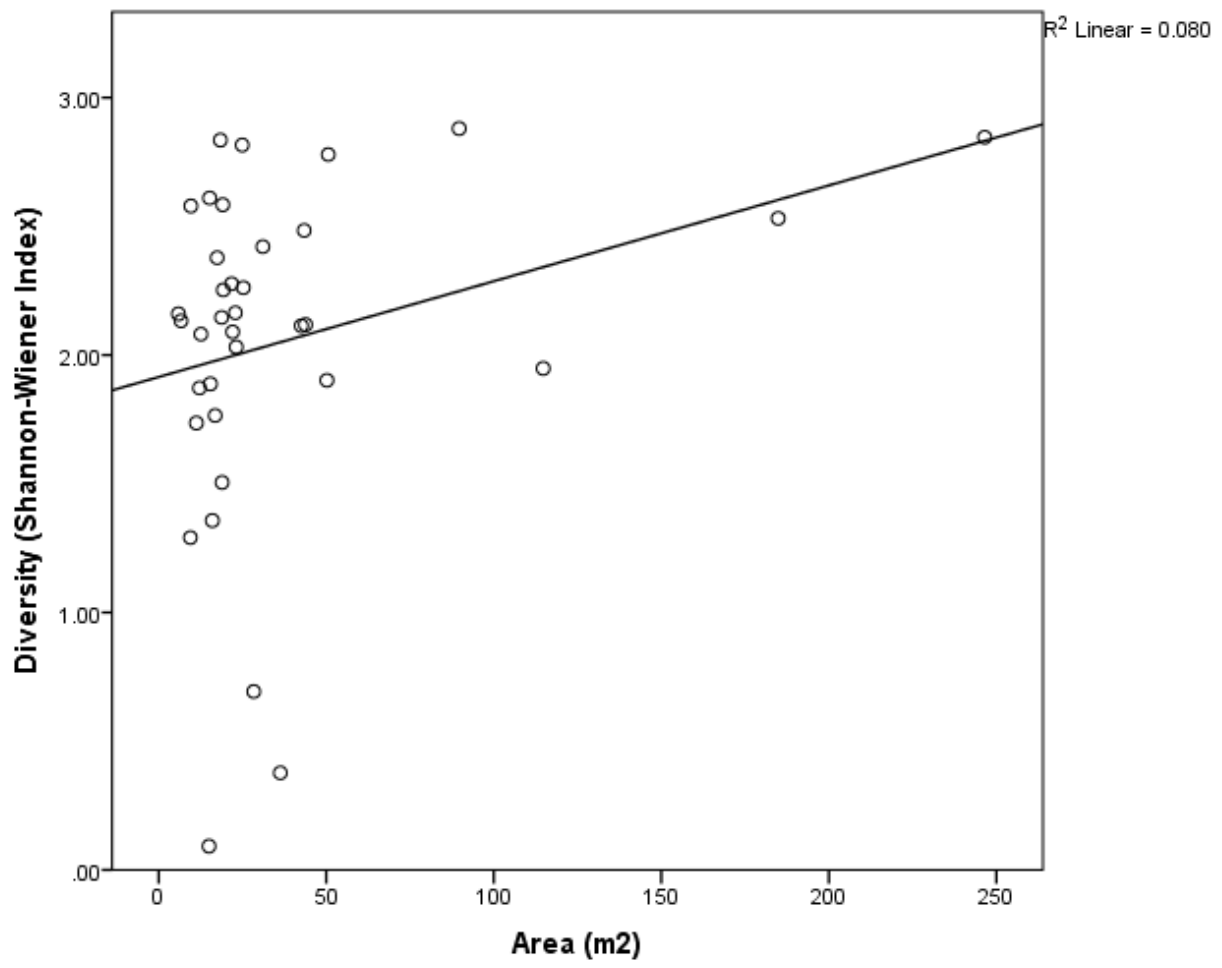

Figure 3. Site diversity as a function of area within each of the 36 sites surveyed.

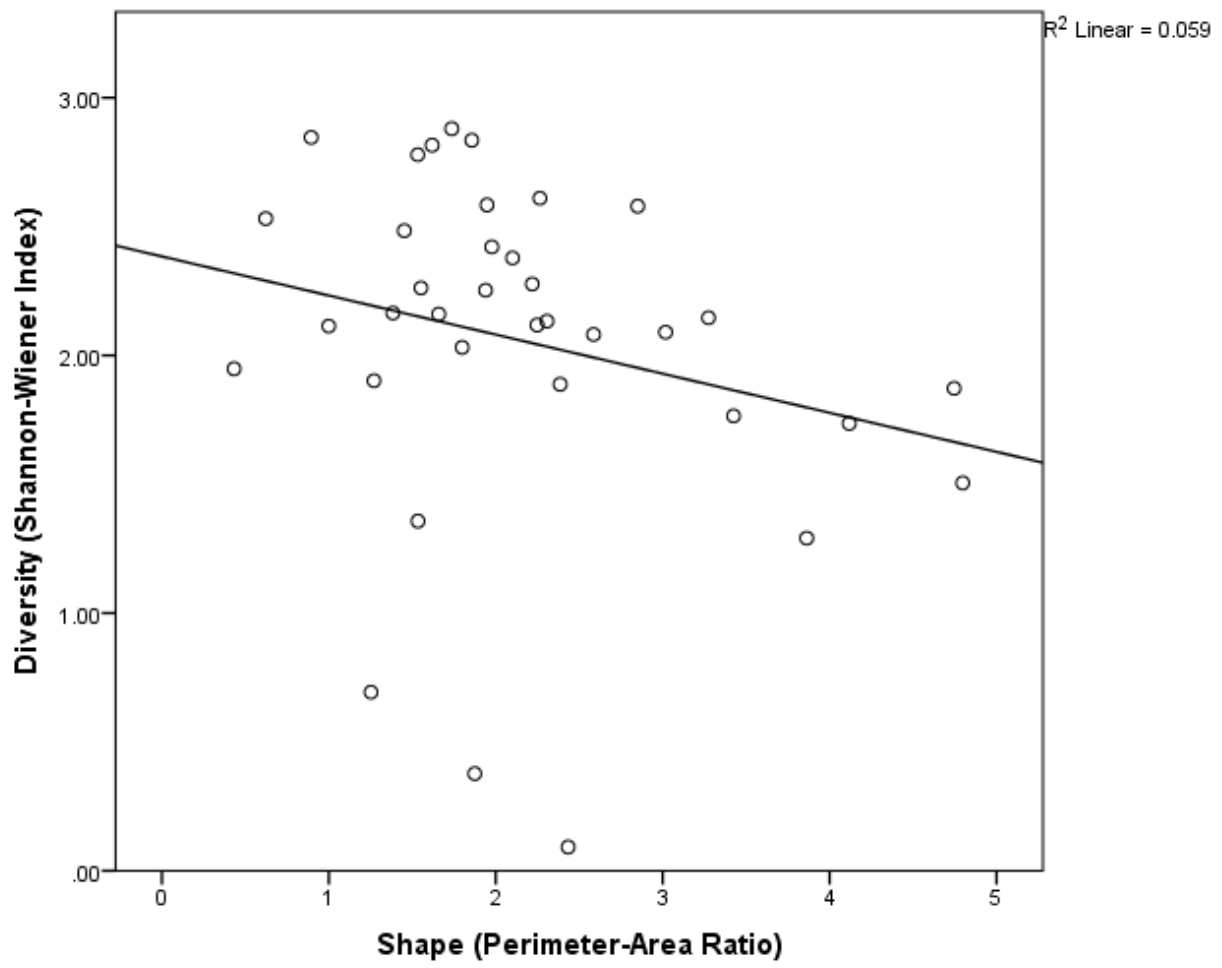

Figure 4. Site diversity as a function of site shape within each of the 36 sites surveyed. 


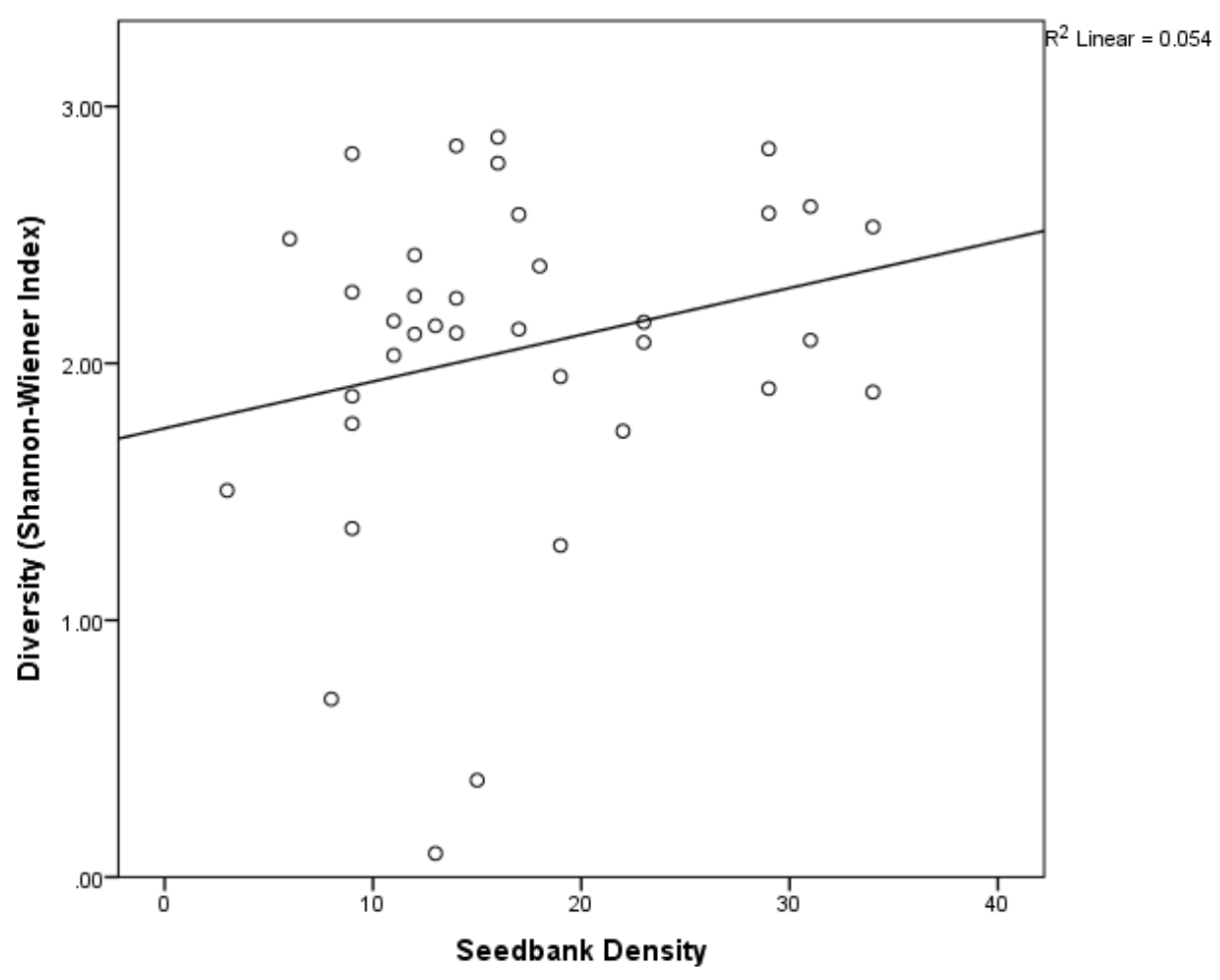

Figure 5. Site diversity as a function of seedbank density (\# seeds $/ 126.63 \mathrm{~cm}^{3}$ ) at each of the 36 sites surveyed.

\section{DISCUSSION}

\section{Ecological Factors}

Seedbank density was the only ecological factor found to play a significant role in predicting biodiversity within sites. This relationship is unsurprising as an increase in species types would also indicate an increase in seed types, some of which may be more readily identifiable. The existing floral composition of sites would be expected to be reflected in the seedbank, especially given the low 
disturbance levels found across the majority of sites. The addition of an emergence measure in future studies would aid in seed identification and help in establishing a direct relationship between seedbank density, composition, observed biodiversity. However, these results highlight the importance of including seedbank analysis in long term monitoring and its potential as a biodiversity indicator (Duelli \& Obrist 2003).

Model 14, the combined effect of disturbance, decomposition, and seedbank on biodiversity, was not contained within the $95 \%$ confidence interval set. Although this is contrary to initial hypotheses it is not unsurprising given the scale of the study sites. Small, fragmented land should theoretically be governed by edge effects and localised disturbance, as has been previously found in New Zealand podocarp-broadleaf forests (Young \& Mitchell 1994). The consistency of the findings of this study with research conducted in less human-dominated environments would indicate that there is potential for a careful and deliberate application of traditional ecological theory to novel, urban ecosystems.

\section{Physical Factors}

Similarly, the finding that area and shape were among the best performing models explaining biodiversity conforms with existing ecological theory based on work done with larger areas (Schwartz et al. 2013; Young \& Mitchell 1994). A negative relationship was found between biodiversity and increases in the perimeter-area ratio. As sites with a larger ratio have an increased perimeter for a comparatively small area, this would indicate an increase in the deleterious species 
effects associated with edge exposure. However, the expression of this negative relationship may also be a result of several indirect physical factors. Site accessibility or visual exposure could theoretically lead to an increase in human involvement. It was thought that increases in exposed edges, especially those surrounded by roads and foot path, would yield higher levels of disturbance. However, disturbance levels were found to be generally low and modelling suggests a poor explanatory power of the variable. This may be indicative of a more complex relationship that was not uncovered in the course of this research.

Additionally, there may be individual species characteristics governing establishment and recruitment within these sites. Native species have the potential to perform more favourably than non-natives within a purposely planted regiment (Berentson 2013), but as this study did not make distinctions between species status it is possible that the high vector pressure represented by roadways is actually a driving force in site biodiversity.

Although small sites $\left(<50 \mathrm{~m}^{2}\right)$ were found to have varying amount of biodiversity, the only three sites with a diversity index of less than 1.00 were all classified as small. Similarly, the only two sites with areas greater than $150 \mathrm{~m}^{2}$ both had diversity indexes over 2.00. Again, this may be indicative of the complexities associated with ecological systems whereby any number of factors may be responsible for the observed characters present at sites. While smaller sites were found to be less consistently diverse than their larger counterparts, they may still represent value for the conservation of habitats and species with a 
naturally-occurring isolated distribution (Schwarz 1999). The effects of increases in an perimeter-area ratio is well documented, yet changes in our understanding of the supposed permanence of such fragmented landscapes has become a cornerstone of restoration ecology and is crucial to our re-imagining of the ecological potential of the urban landscape (Young 2000).

\section{Socioeconomic Factors}

Deprivation index was not found to be a significant predictor of site biodiversity. The scope of this research did not extend to population measures as explicit models which has been shown to have a negative correlation with biodiversity potential as well as ecosystem services (Tratalos et al. 2007). While previous research has shown that increases in residential vegetation can exhibit a strong relationship with localised socio-economics (Martin et al. 2004), no such pattern was detected during the course of this study. It was surprising that the deprivation index, which varied significantly across sites, was not correlated to biodiversity. It is possible that the topographical nature and comprehensive planning of the Wellington region (i.e. Outer Green Belt), designed for city-wide access to greenspace (Beatley 2016), reduces the inequity of experience often associated with socioeconomic gaps. Similarly, although socio-economic boundaries in New Zealand cities have been found to be significantly related to accessible local biodiversity, much of this disparity is attributed to mature, established gardens on private property (Hand et al. 2016), and thereby removed from the scope of this study. 


\section{Further Research}

Ultimately, the restoration value of small urban road reserves will be largely governed by local priorities. Small urban patches have the same associated risks that patchiness has long represented in non-urban landscapes, acting as ecological sinks which negatively affect population growth rates (Pulliam 1988). Although urban patches may support higher proportions of exotic species than rural counterparts, levels of biodiversity (both native and exotic) can be expected to drop precipitously over time as succession events move away from pioneer species (Angold et al. 2006). Small patches within an urban landscape can increase select species diversity but proximity to larger sources help eliminate the sink potential of small, isolated urban areas increasing overall diversity within the urban matrix (Loss et al. 2009). Examining small habitats within the context of the larger urban matrix may help inform observed levels of biodiversity as well as overall ecological functioning.

The ramifications this has for urban greening initiatives is currently under researched and, as such, long-term monitoring programmes are being developed and implemented (Pickett et al. 2008).To fully understand ecological functioning and interaction dynamics within restoration sites multiple measurements are required over significant periods of time (Ruiz-Jean \& Aide 2005). The obvious drawback to explicit long term monitoring schemes lies in increased cost and resource investment which might explain the prevalence of one-off experimental designs. 
The longevity of urban patches is largely determined through city planning and development as well as community engagement. Although the rationales associated with urban greenspace preservation and restoration is well established (Clewell \& Aronson 2006; Peters et al. 2015; Svendsen \& Campbell 2008), further research is needed to quantify the ecological value of urban greening efforts. This is explored in the following chapter. 


\section{Chapter 3}

\section{THE ECOLOGICAL EFFECTS OF COMMUNITY PLANTING OVER A 25 YEAR PERIOD IN WELLINGTON, NEW ZEALAND}

\section{INTRODUCTION}

Urban greenspaces are frequently targeted by community restoration groups in a variety of ways (e.g. native planting, weeding, public policy initiatives, increased aesthetics), and are thus considered to be major drivers of urban vegetation (Conway et al. 2011). Recent trends have shown an increase in the level of community-based contributions to restoration and conservation efforts, largely attributable to expanding educational outreach and economic considerations (Bramston et al. 2011). Additionally, volunteer community restoration efforts are often designed with social, ecological, and economic considerations (Clewell \& Aronson 2013). Engaging the public can also ease many of the complexities and political controversies associated with ecological restoration efforts, leading to enduring and self-sustaining, citizen science-based projects (Buzier et al. 2012; Theobald et al. 2015).

Small-scale restoration efforts in particular offer not only the most accessible avenue for volunteer involvement, but may also provide urban ecologists a unique opportunity to evaluate the socio-ecological benefits of such engagement in an experimental context. Sites which are manipulated through 
planting efforts are likely to be the target of future community attention which may consist of continued planting, weeding, or recreation (Tzoulas et al. 2007; Krasny et al. 2014). These activities may contribute significantly to levels of biodiversity, both directly, as would be seen with purposeful native planting, and indirectly, through an increase in localised disturbance and altered decay rates. Community planting programmes therefore provide a unique opportunity for research of both ecological effect as well as an opportunity to examine social impact on the community.

Urban greening efforts targeting comprehensive green networks on city scales have been implemented in a number of European and America cities, and, in recent years have begun to take shape throughout New Zealand (Viles \& Rosier 2001). The Wellington City Council's Free Plants Programme (FPP) has been operating for 25 years providing individual plants to local residents to be planted on public land, most often small roadside reserves. These reserves border public and private land and represent an excellent post hoc opportunity to examine the ecological effects of an urban greening scheme.

In a review of 301 articles presenting restoration efforts and success indices, Wortley et al. (2013) found that $98.5 \%$ of studies indicated an ecological focus, with only $2 \%$ of those also containing an examination of related social aspects or impacts. A similarly sized study examined the self-proclaimed objectives of community restoration groups and found that $72.9 \%$ of groups prioritise social objectives, the most common being 'community-building' and 'education and awareness' (Peters et al. 2015). The stark differences between 
these findings illustrate the need for comprehensive research into the socioecological effects of community-based restoration activities and an examination of the measurable ecological impacts of volunteer involvement. This will help to ensure that both ecological health and continued support to/from volunteer organisation continues unabated (Peters et al. 2015).

Successful landscape connectivity within an urban system requires regionally specific ecological analysis (Viles \& Rosier 2001). The establishment of individual urban greening initiatives across a spectrum of social and ecological conditions will facilitate the development of broader theory, and in turn, inform future management and development decisions. There is considerable evidence supporting the ecological value that unmanaged land represents in the urban landscape: allowing urban areas to vegetate spontaneously without human influence can support habitat provisioning for plant diversity (Robinson \& Lundholm 2012) and arthropod assemblages (Small et al. 2003; Gödde et al. 1995). As restoration efforts involve considerable time and resources the impact they have must be carefully evaluated. Local diversity and ecological functioning measures are among the most commonly assessed metrics in determining the success of ecological restoration projects (Wortley et al. 2013). These endeavours can have demonstrable effects on ecosystem functioning including the support of local biodiversity (Cooper et al. 2007). This chapter examines planting regime variation within FPP sites and the relationship between these variables and ecosystem function and biodiversity.

The primary question being explored is as follows: 
How do planting efforts, defined as the number of years a given site has been planted and the number of individual plants provided to that site, over a 25 year period effect ecological functioning and biodiversity within small roadside reserves?

It was hypothesised that planting intensity (combined variation in number of planting years and planted individuals) is unlikely to affect ecological function including biodiversity. However, it is possible that the repeated addition of large numbers of individual plants may increase local biodiversity, especially on a short term basis. As a result of this, recently planted sites may boast temporarily high diversity levels and this may lead to significant correlations between planting intensity and one or more dependant variables, the most likely of which would be biodiversity.

\section{METHODS}

The aim of this chapter was to assess whether there is a relationship between the planting history of sites and measures of ecological function (as outlined in the previous chapter) and biodiversity. The primary question being explored is as follows:

Does planting intensity (planting years and number of planted individuals) within the Wellington City Council's Free-Plants Program (FPP) contribute to local biodiversity and ecosystem function? 


\section{Data Collection}

Planting intensity was assessed through two distinct measures: the number of years a given site had been subjected to planting through the FPP (planting years) and the cumulative number of individual plants provided (planted individuals) (Table 8). Determining both measures presented similar challenges in that the available database information was organised not in accordance with planting location, but rather residential data regarding the individual requesting plants. A thorough database investigation and repeated site visits indicated that any given site may have been subjected to planting by multiple members of the neighbourhood or community, the involvement of whom would not be directly linked to the selected site (original site selection was largely informed through the specificity of targeted site descriptions). To compensate for this planting data for any given site was expanded to include recorded incidences of planting which exhibited a strong likelihood that the selected site was the targeted destination. Properties were often listed as programme recipients in multiple years and any recurring property with conflicting targeted site locations was not included in the cumulative numbers used in the final analysis. No property was assumed to have been involved in the planting of a site if located more than $100 \mathrm{~m}$ from the site, unless explicitly indicated in the database. 
Table 8

Historical site variables surveyed

\begin{tabular}{lcc}
\hline Variable & Category & Methods \\
\hline Planting Years & Historical Context & Retrieved from existing database \\
& & sources* \\
Planted Individuals & Historical Context & Retrieved from existing database \\
& & sources* \\
\hline
\end{tabular}

*Data provided by Wellington City Council (Berhampore Nursery records for years 1990-2015)

Statistical Methods

A MANOVA was used to test the relationship between the number of years a site had been planted and the total number of individuals provided with measures of decomposition, disturbance, seedbank density and biodiversity. Predictor variables were tested separately as a combined analysis failed Levene's Test. Univariate testing was conducted to determine any significance of betweensubjects effects (Bolker et al. 2008).

\section{RESULTS}

Descriptive Statistics

Historical context variables measured at each site varied widely (Table 9). The number of planted individuals at each site ranged from $10-601$ with a mean of 89.4. 34 out of 35 surveyed sites received less than 200 individual plants over 
the 25 year data period with $37.1 \%$ of sites receiving less than 50 individual plants

(Figure 6). The number of years a site was planted ranged from $1-6$ years with a mean of 2.5 . $31.4 \%$ of surveyed sites were determined to have been planted once, while a single site was found to have been planted on more than 5 separate years (Figure 7). Both maximum values for planting years and planted individuals were captured in the same site. A significant correlation was found between planting years and planted individuals (Pearson $r=0.819, p<0.01$ ).

Planting years and planted individuals frequencies can be found in Figure 6 and Figure 7.

Table 9

Summary statistics for historical site variables surveyed

\begin{tabular}{lcc}
\hline & Planting Years & Planted Individuals \\
\hline Mean & 2.5 & 89.4 \\
Standard Error & 0.3 & 17.3 \\
Median & 2.0 & 58.0 \\
Standard Deviation & 1.5 & 102.3 \\
Skewness & 0.9 & 3.9 \\
Range & 5.0 & 591.0 \\
Minimum & 1.0 & 10.0 \\
Maximum & 6.0 & 601.0 \\
\hline
\end{tabular}




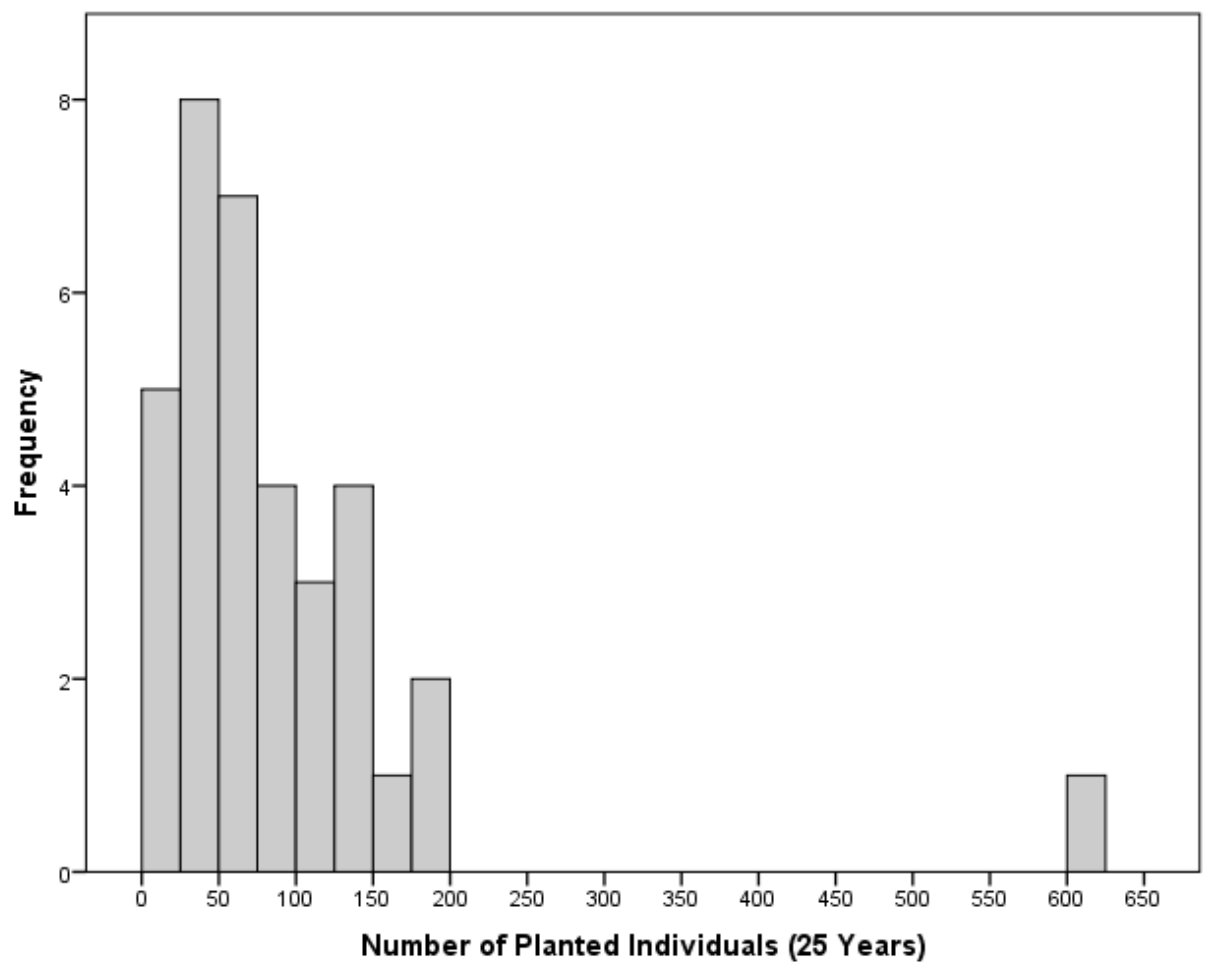

Figure 6. Frequency distribution for the number of planted individuals

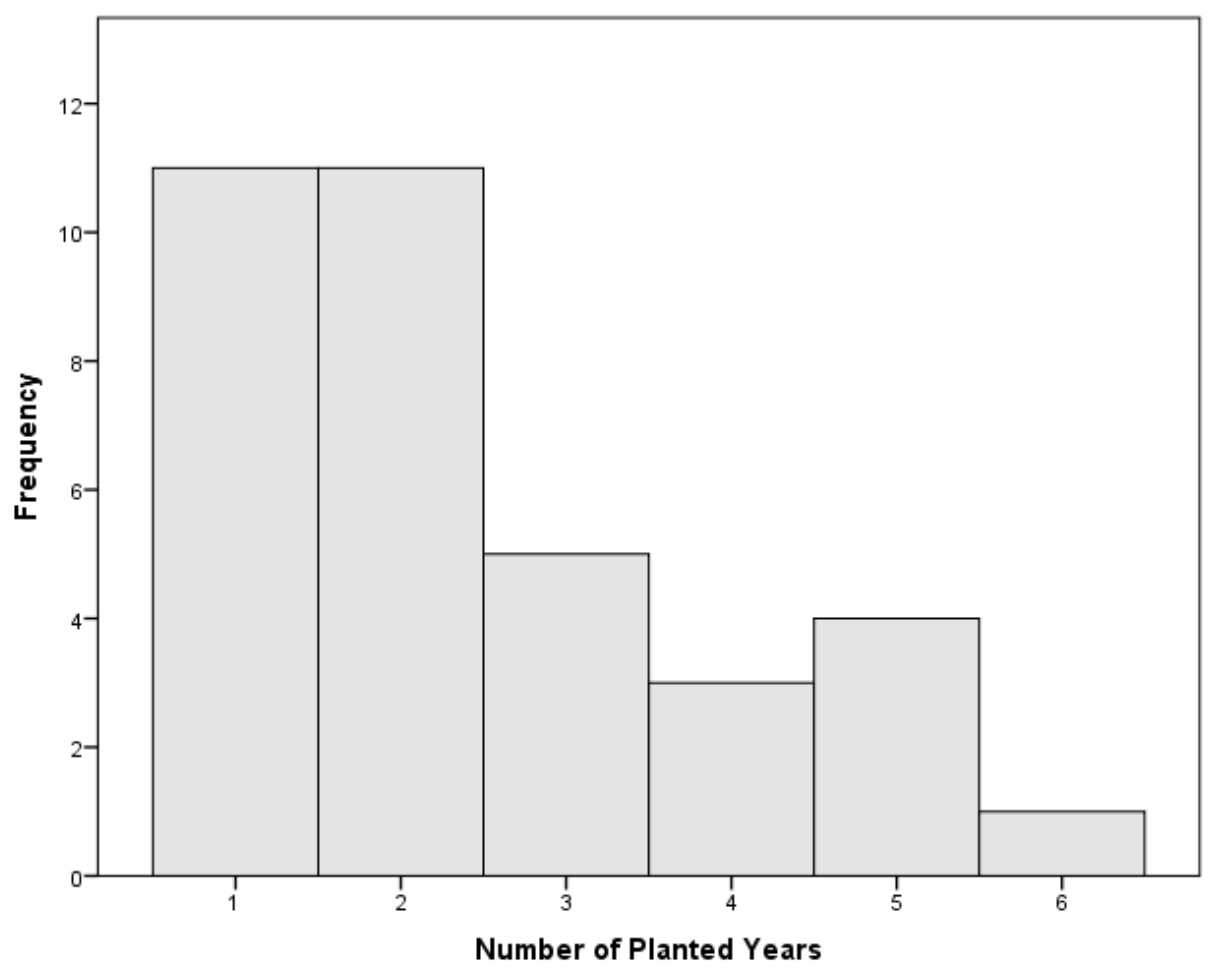

Figure 7. Frequency distribution for the number of planting years 


\section{Planted Individuals}

The number of planted individuals did not explain combined measures of biodiversity and ecosystem function (Pillai's Trace $=0.201, F_{30,4}=1.881, p=.140$ ). Univariate testing found a somewhat significant positive relationship between the number of planted individuals and biodiversity $\left(F_{33,1}=3.536, p=.069\right)$. No significant relationship was found between the number of planted individuals and disturbance $\left(F_{33,1}=1.535, p=.224\right)$. No significant relationship was found between the number of individuals planted and seedbank density $\left(F_{33,1}=0.045, p=\right.$ .833). No significant relationship was found between the number of planted individuals and decomposition $\left(F_{33,1}=1.699, p=.201\right)$

Although not statistically significant, a slight negative relationship was described for both seedbank density and disturbance as a function of an increase in planted individuals, while a slight positive relationship was described for decomposition as a function of the same measure (Figure 8).

A potential outlier was identified and can be seen in Figure 8. Multivariate testing was re-run without this site and no significance was found (Pillai's Trace $=$ $\left.0.194, F_{29,4}=1.473, p=.236\right)$. 

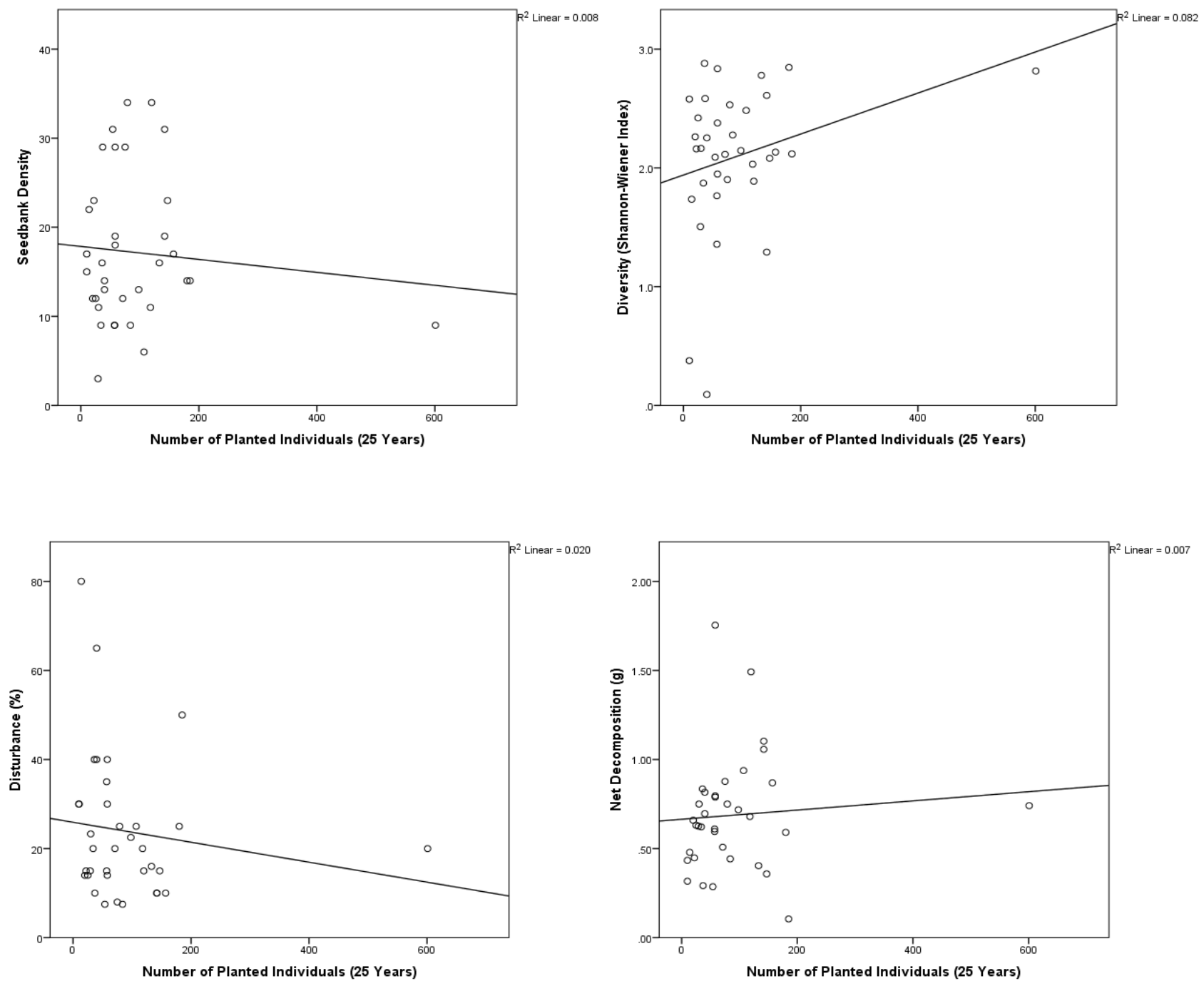

Figure 8. Four ecological factors as a function of the number of individuals planted at each study site over a 25 year period.

Planting Years

The number of planting years come close to explaining combined measures of biodiversity and ecosystem function (Pillai's Trace $=.245, F_{30,4}=2.429, p=.069$ ). Univariate testing found a near significant negative relationship between the 
number of planting years and disturbance $\left(F_{33,1}=4.092, p=.051\right)$. No significant relationship was found for the number of planting years and decomposition $\left(F_{33,1}=\right.$ $0.034, p=.885)$. No significant relationship was found for the number of planting years and seedbank density $\left(F_{33,1}=0.790, p=.384\right)$. No significant relationship was found between number of planting years and biodiversity $\left(F_{33,1}=1.654, p=.207\right)$ (Figure 9).

Multivariate testing was again re-run without the site identified as a potential outlier and no significance was found (Pillai's Trace $=0.222, F_{29,4}=2.063$, $\mathrm{p}=.112)$ 

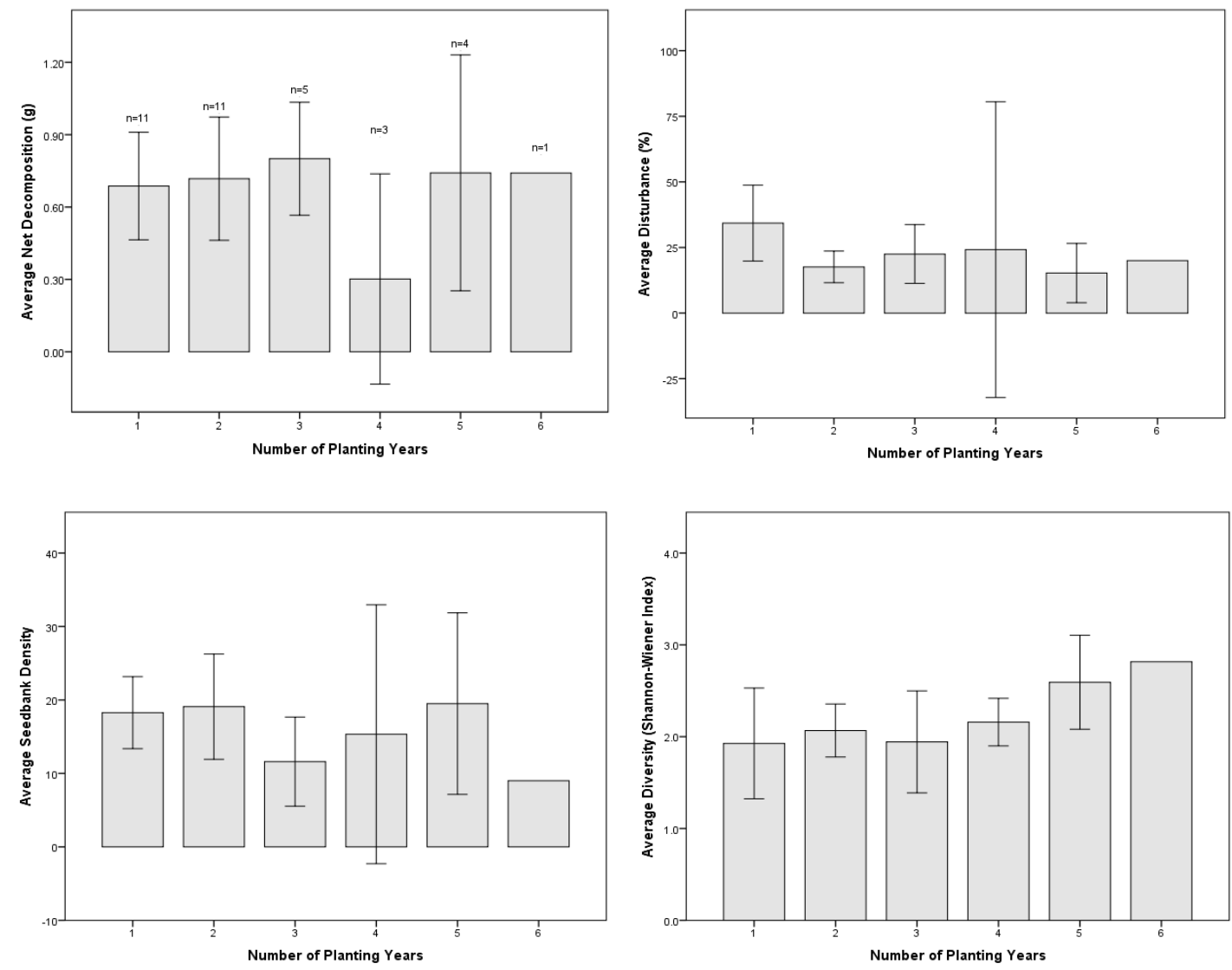

Error bars represent $95 \% \mathrm{CI}$

Figure 9. The average measure of four ecological factors as a function of the number of years a given site was planted.

\section{DISCUSSION}

It is not surprising that the number of planting years and planted individuals was found to be strongly correlated; fidelity to any particular site would likely result in long-time residents repeatedly requesting plants for a specific location. Accepting this, the most salient question becomes the extent to which repeated greening efforts affect these sites. Although planting intensity 
(combined measure of planting years and planted individuals) was not found to have a significant effect on ecological functions and biodiversity, there is weak support for a relationship between these measures and planting years.

\section{Planting Years}

Interestingly, only the disturbance measure showed a significant relationship to planting years. As the number of years a site was planted increased reduced levels of disturbance were observed. Repeated planting can be considered a site commitment on the behalf of residents, which may explain this result. Prolonged greening efforts can impart significant feelings of stewardship towards residents (Armstrong 2000), and as such, residents may be more vigilant of site degradation, augmenting planting efforts beyond those associated with the FPP. Similarly, continued planting efforts may be indicative of increased residence time or neighbourhood age which have also been linked to increases in biodiversity and greenspace (Loss et al. 2009). Although sites planted in conjunction with the FPP are removed from public works lists of mowing and weeding targets, there was evidence of clearing activity found in the course of this research which may have contributed to measured disturbance.

\section{Planted Individuals}

The only somewhat significant relationship found for planted individuals was site biodiversity. As no such relationship was described for planting years, these results support the initial hypothesis that increasing the number of plants 
provided to site would increase the measure of site biodiversity, especially on an immediate basis. Combining the lapsed time between the most recent planting events with repeated biodiversity measures would provide insight into ongoing mortality rates associated with this urban greening initiative. Previous research has shown that survival rates of planted seedlings in the Wellington region is influenced by species-specific and human factors (Berentson 2013), and may be improved through a concerted focus on providing larger, more robust seedlings (Anton et al. 2015).

The FPP has transitioned to providing almost entirely native plants in recent years, maintaining high stocks in conjunction with the Berhampore Nursery. In general, participation in the FPP is largely correlated with an existing knowledge of horticulture, which likely extends to the local suitability of various plants (Berentson 2013). This is promising as recent research has shown that urban greening initiatives are often limited by residents unaware of native plant availability and a nursery trade with limited supply (Torres-Camacho et al. 2017).

\section{Future Research}

Community-based urban greening efforts often lack a goal-driven operating framework and may benefit from an adaptive co-management approach (Olsson \& Folke 2004). Although urban greening initiatives are often community-led and in response to a catalytic event (i.e. neighbourhood degradation or natural disaster/disturbance) (Krasny et al. 2014), the involvement of scientific agencies 
and local governing bodies can result in longer-lasting, wider-impacting restoration efforts (Svendsen \& Campbell 2008; Ostrom \& Cox 2010).

This research has shown preliminary evidence that the level of planting intensity within small roadside reserves have not measurably affected the ecological function and biodiversity of the study sites. There has been, however, no current effort to ascertain any influence upon the larger urban landscape as a result of local planting efforts. Similar programmes have prioritised large areas to act as ecological 'hubs', facilitating a source dynamic thereby aiding in biological diversification and species movement across the urban gradient (Walmsley 2006). While there is undeniable value in engaging with a resident's desire to beautify their local surrounds and increasing feelings of stewardship with nature (Andersson et al. 2014; Chapin et al. 2010), the extent to which this aides in the creation of sustained refuges for priority taxa is currently unquantified. Future research should focus on the extent to which the FPP supports increased landscape connectivity between planting sites.

As no attempt was made to ascertain site age as a product of land development, it is possible that some variation measured within sites is also correlated with non-FPP related succession dynamics. The age of urban patches has been shown to positively affect diversity levels of arthropods (Mclntyre 2000), as has the age of neighbourhoods been positively correlated with diversity levels of plants (Martin et al. 2004). Age dynamics associated with small-scale urban restoration warrants further study in the Wellington region. 
Expected increases in city size and density will place additional stresses and value on urban ecosystem function and services, underpinning the need for sustainable socio-ecological frameworks (Chapin et al. 2010; Savard et al. 2000). Compounded with current research gaps associated with community planting programmes in countries other than the USA (Guitart et al. 2012), there is a growing need for comprehensive research with an early emphasis on a local and city-level scale. 


\section{Chapter 4}

\section{CONCLUSIONS}

Modelling conducted over the course of this research indicate that the size and shape of roadside reserves are the most important predictors of biodiversity. Holding with traditional ecological theory, the area and shape of reserves describe potential recruitment limitations associated with edge effects and habitat fragmentation. This functional similarity between small urban patches and larger ones outside of the urban landscape suggests the need for additional research into the effect of scale when examining urban habitat. The novelty of urban ecosystems in the field of ecology is predicated on an assumption of dissimilarity, the extent of which will only become better understood. Additionally, further research into seedbank analysis as a biodiversity indicator for urban habitat is recommended, specifically within the context of a long-term monitoring framework.

Increases in planting years were associated with a reduction in site disturbance and increases in planted individuals were associated with higher biodiversity. These findings support the FPP goals and will hopefully aid in future management decisions. Sites targeted for future urban greening may benefit from efforts which utilise specific restoration goals. As the edges of roadside reserves 
are generally paved roads or footpaths a concerted focus towards planting along these edges may provide site buffering and the promotion of biodiversity.

Combining environmental, social and historical factors may present a more comprehensive understanding of the factors affecting diversity within and across an urban landscape. Understanding the complexities governing urban ecosystems is critical for sustainable greenspace development. Key issues include individual patch dynamics and position within urban landscape, biological indicators, and the informed development of a comprehensive, locally specific, socio-ecological framework.

The value of urban greenspace is subjective; ecologists, local managers, community groups and stakeholders may possess varying metrics for successful urban greening. While the definition of success may differ, they are not necessarily mutually exclusive. The establishment and maintenance of urban biodiversity and robust ecological functioning requires a "participatory management" approach, incorporating socio-ecological dynamics that can result in "different and potentially complementing profiles" within the urban landscape (Andersson et al. 2014, p.449).

The adaptation of traditional ecology theory to novel urban ecosystems is as complex as it is critical: urban landscapes are complex mosaics in which humans and our constructs act as both backdrops and drivers of ecological function and habitat dynamics. Any application of an "ecology of cites" methodology to urban restoration must begin with the acceptance that humans influence the 
connectivity and organisation of habitat patches as well as the assemblage of species within these patches (Niemelä et al. 2009). As biotic succession is both directly, and indirectly, influenced by human activity (Bradshaw 2003), a successful framework for the future of greenspace research, planning, and management requires such considerations. As research has shown that biodiversity gains associated with ecological restoration initiatives can be significantly compromised when site selection is not based on biodiversity objectives (Mason et al. 2012), the promotion of healthy ecological functioning and biodiversity within urban greenspace will require ongoing community engagement, biological monitoring, and explicit restoration goals. 


\section{REFERENCES}

Abella SR, Chiquoine LP, Vanier CH (2013) Characterising soil seed banks and relationships to plant communities. Plant Ecology 214: 703-715

Alberti M (2008) Advances in urban ecology: integrating humans and ecological processes in urban ecosystems. Springer, New York

Alberti M, Marzluff JM, Shulenberger E, Bradley G, Ryan C, Zumbrunnen C (2003) Integrating humans into ecology: opportunities and challenges for studying urban ecosystems. Bioscience 53: 1169-1179

Albrecht H, Eder E, Langbehn T, Tschiersch C (2011) The soil seed bank and its relationship to the established vegetation in urban wastelands. Landscape and Urban Planning 100: 87-97

Alvey AA (2006) Promoting and preserving biodiversity in the urban forest. Urban Forestry and Urban Greening 5: 195-201

Andersson E, Barthel S, Borgström S, Colding J, Elmqvist T, Folke C, Gren Å (2014) Reconnecting cities to the biosphere: stewardship of green infrastructure and urban ecosystem services. Ambio 43: 445-453

Angold PG, Sadler JP, Hill MO, Pullin A, Rushton S, Austin K et al. (2006) Biodiversity in urban habitat patches. Science of the Total Environment 360: 196-204

Anton V, Hartley S, Wittmer HU (2015) Survival and growth of planted seedlings of three native tree species in urban forest restoration in Wellington, New Zealand. New Zealand Journal of Ecology 39: 170-178

Armstrong D (2000) A survey of community gardens in upstate New York: implications for health promotion and community development. Health and Place 6: 319-327

Atkinson J, Salmond C, Crampton P (2014) NZDep2013 Index of Deprivation. Wellington: Department of Public Health, University of Otago, Wellington

Attiwill PM (1994) The disturbance of forest ecosystems: the ecological basis for conservative management. Forest Ecology and Management 63: 247-300 
Beatley T (2016) Handbook of biophilic city planning and design. Island Press, Washington, DC

Berentson P (2013) Twenty years of providing free plants in an urban New Zealand setting: what affects community participation and planting success? (Unpublished master's thesis) Victoria University of Wellington, Wellington

Bolker BM, Brooks ME, Clark CJ, Geange SW, Poulsen JR, Stevens MHH, White JS (2008) Generalized linear mixed models: a practical guide for ecology and evolution. Trends in Ecology and Evolution 24: 127-135

Bonnington C, Gaston KJ, Evan KL (2013) Fearing the feline: domestic cats reduce avian fecundity through trait-mediated indirect effects that increase nest predation by other species. Journal of Applied Ecology 50: 15-24

Bonthoux S, Brun M, Di Petro F, Greulich S, Bouche-Pillon S (2014) How can wastelands promote biodiversity in cities? A review. Landscape and Urban Planning 132: 79-88

Bradshaw AD (2003) Natural ecosystems in cities: a model for cities in ecosystems. In: Berkowitz AR, Nilon CH, KS Hollweg (Eds.) Understanding urban ecosystems. Springer-Verlag, New York

Bramston P, Pretty G, Zammit C (2011) Assessing environmental stewardship motivation. Environment and Behavior 43: 776-788

Burke SM, Mitchell N (2007) People as ecological participants in ecological restoration. Restoration Ecology 15: 348-350

Burnham K, Anderson D (2002) Model selection and multimodel inference: a practical information-theoretic approach. $2^{\text {nd }}$ edn. Springer-Verlag, New York

Buzier M, Kurz T, Ruthrof K (2012) Understanding restoration volunteering in a context of environmental change: in pursuit of novel ecosystems or historical analogues> Human Ecology 40: 153-160

Carreiro MM, Howe K, Parkhurst DF, Pouyat RV (1999) Variation in quality and decomposability of red oak leaf litter along an urban-rural gradient. Biology and Fertility of Soils 30: 258-268

Chapin FS, Carpenter SR, Kofinas GP, Folke C, Abel N, Clark WC et al. (2010) Ecosystem stewardship: sustainability strategies for a rapidly changing planet. Trends in Ecology and Evolution 25: 241-249 
Chapin FS, Matson PA, Vitousek PM (2011) Principles of Terrestrial Ecosystem Ecology. Springer-Verlag, New York.

Clewell AF, Aronson J (2006) Motivations for the restorations of ecosystems. Conservation Biology 20: 420-428

Clewell AF, Aronson J (2013) Ecological restoration: principles, values, and structure of an emerging profession. $2^{\text {nd }}$ edn. Island Press, Washington, DC

Connell JH (1978) Diversity in tropical rainforest and coral reefs. Science 199: 13021310

Conway TM, Shakeel T, Atallah J (2011) Community groups and urban forestry activity: drivers of uneven canopy cover? Landscape and Urban Planning 101: $321-329$

Cooper CB, Dickinson J, Phillips T, Bonney R (2007) Citizen science as a tool for conservation in residential ecosystems. Ecology and Society 12: 11

Cornelis J, Hermy M (2004) Biodiversity relationships in urban and suburban parks in Flanders. Landscape and Urban Planning 69: 385-401

Craul J (1992) Urban soil in landscape design. Wiley, New York

Duelli P, Obrist MK (2003) Biodiversity indicators: the choice of values and measures. Agricultural Ecosystems and Environment 98: 87-98

Eriksson A, Eriksson O (1997) Seedling recruitment in semi-natural pastures: the effect of disturbance, seed size, phenology and seed bank. Nordic Journal of Botany 17: 469-482

Freeman C, Buck O (2003) Development of an ecological mapping methodology for urban areas in New Zealand. Landscape and Urban Planning 63: 161-173

Gaston, KJ (2010) Urban ecology. In: KJ Gaston (Ed.) Urban Ecology. Cambridge University Press, New York, NY

Gaston, KJ, Davies, ZG, and Edmonson, JL (2010) Urban environments and ecosystem functions. In: KJ Gaston (Ed.) Urban Ecology. Cambridge University Press, New York, NY

Gödde M, Richarz N, Walter B (1995) Habitat conservation and development in the city of Dusseldorf (Germany). In: Sukopp H, Numata M, A Huber (Eds.) Urban ecology as the basis for urban planning. SPB Academic Publishing, Amsterdam 
Graham MH (2003) Confronting multicollinearity in ecological multiple regression. Ecology 84: 2809-2815

Grimm NB, Faeth SH, Golubiewski NE, Redman CL, Wu J, Bai X, Briggs JM (2008) Global change and the ecology of cities. Science 319: 756-760

Grimm NB, Grove JM, Pickett STA, Redman CL (2000) Integrated approaches to long-term studies of urban ecological systems. BioScience 50: 571-584

Guitart D, Pickering C, Byrne J (2012) Past results and future directions in urban community gardens research. Urban Forestry and Urban Greening 11: 364373

Hand KL, Freeman C, Seddon PJ, Stein A, van Heezik Y (2016) A novel method for fine-scale biodiversity assessment and prediction across diverse urban landscapes reveals social deprivation-related inequalities in private, not public spaces. Landscape and Urban Planning 151: 33-44

Hättenschwiler S, Tiunov AV, Scheu S (2005) Biodiversity and litter decomposition in terrestrial ecosystems. Annual Review of Ecology, Evolution, and Systematics 36: 191-218

Helzer CJ, Jelinski DE (1999) The relative importance of patch area and perimeterarea ratio to grassland breeding birds. Ecological Applications 9: 1448-1458

Heneghan L, Umek L, Bernau B, Grady K, latropulos J, Jabon D, Workman M (2009) Ecological research can augment restoration practice in urban areas degraded by invasive species - examples from Chicago Wilderness. Urban Ecosystems 12: 63-77

Hooper DU, Chapin FS, Ewel JJ, Hector A, Inchausti P, Lavorel S et al. (2005) Effects of biodiversity on ecosystem functioning: a consensus of current knowledge. Ecological Monographs 75: 3-35

Hope D, Gries C, Zhu W, Fagan WF, Redman CL, Grimm NB et al. (2003) Socioeconomics drives urban plant diversity. Proceedings of the National Academy of Sciences of the USA 100: 8788-8792

Horák J (2016) Suitability of biodiversity-area and biodiversity-perimeter. Urban Ecosystems 19: 131-142

Hostetler M, Allen W, Meurk C (2011) Conserving urban biodiversity: creating green infrastructure is only the first step. Landscape and Urban Planning 100: $369-371$ 
Iverson LR, Cook EA (2000) Urban forest cover of the Chicago region and its relation to household density and income. Urban Ecosystems 4: 105-124

Johnson JB, Omland KS (2004) Model selection in ecology and evolution. Trends in Ecology and Evolution 19: 101-108

Koh LP, Sodhi NS (2004) Importance of reserves, fragments, and parks for butterfly conservation in a tropical urban landscape. Ecological Applications 14: 1695-1708

Kowarik I (2011) Novel urban ecosystems, biodiversity, and conservation. Environmental Pollution 159: 1974-1983

Kowarik I, Fischer LK, Saumel I, von der Lippe M, Weber F, Westermann JR (2011) Plants in Urban Settings: from patterns to mechanisms and ecosystem services. In: W Endlicher et al. (Eds.) Perspectives in Urban Ecology (pp. 135-166). Springer-Verlag, Berlin

Krasny ME, Russ A, Tidball KG, Elmqvist T (2014) Civic ecology practices: participatory approaches to generating and measuring ecosystem services in cities. Ecosystem Services 7: 177-186

Loss SR, Ruiz MO, Brawn JD (2009) Relationships between avian diversity, neighbourhood age, income, and environmental characteristics of an urban landscape. Biological Conservation 142: 2578-2585

Luck GW, Smallbone LT (2010) Species diversity and urbanisation: patterns, drivers and implications. In: KJ Gaston (Ed.) Urban Ecology. Cambridge University Press, New York, NY

Martin CA. Warren PS, Kinzig AP (2004) Neighborhood socioeconomic status is a useful predictor of perennial landscape vegetation in residential neighbourhoods and embedded small parks of Phoenix, AZ. Landscape and Urban Planning 69: 355-368

Mason NWH, Ausseil AGE, Dymond JR, Overton JM, Price R, Carswell FE (2012) Will use of non-biodiversity objectives to select areas for ecological restoration always compromise biodiversity gains? Biological Conservation 155: 157168

McDonnell M, Hahs AK (2008) The use of gradient analysis studies in advancing our understanding of the ecology of urbanizing landscapes: current status and future directions. Landscape Ecology 23: 1143-1155 
McDonnell MJ, Hahs AK (2013) The future of urban biodiversity research: moving beyond the 'low-hanging fruit'. Urban Ecosystems 16: 397-409

McDonnell M, Hahs AK, Breuste JH (2009) Ecology of cities and towns: a comparative approach. Cambridge University Press, New York

McKinney ML (2006) Urbanization as a major cause of biotic homogenization. Biological Conservation 127: 247-260

McIntyre NE (2000) Ecology of urban arthropods: a review and a call to action. Annals of the Entomological Society of America 93: 825-835

McNaughton SJ (1977) Diversity and stability of ecological communities: a comment on the role of empiricism in ecology. The American Naturalist 111: $515-525$

Meyer JL (1997) Conserving ecosystem function. In STA Pickett et al. (Eds.) The ecological basis of conservation (pp. 136-145). Chapman and Hall, New York

Muller JN, Loh S, Braggion L, Cameron S, Firn JL (2014) Diverse urban plantings managed with sufficient resource availability can increase plant productivity and arthropod diversity. Frontiers in Plant Science 5: 1-10

Niemelä J (2014) Ecology of urban green spaces: the way forward in answering major research questions. Landscape and Urban Planning 125: 298-303

Niemelä J, Kotze DJ, Yli-Pelkonen V (2009) Comparative urban ecology: challenges and possibilities. In: McDonnell MJ, Hahs AK, Breuste JH (eds) Ecology of cities and towns: a comparative approach. Cambridge University Press, New York

Nowak DJ, Crane DE (2002) Carbon storage and sequestration by urban trees in the USA. Environmental Pollution 116: 381-389

Olsson P, Folke C (2004) Adaptive comanagement for building resilience in socioecological systems. Environmental Management 34: 75-90

Ostrom E, Cox M (2010) Moving beyond panaceas: a multi-tiered diagnostic approach for social-ecological analysis. Environmental Conservation 37: 451-463 
Overdyck E, Clarkson BD (2012) Seed rain and soil seed banks limit native regeneration within urban forest restoration plantings in Hamilton City, New Zealand. New Zealand Journal of Ecology 36: 177-190

Pataki DE, Carreiro MM, Cherrier J, Grulke NE, Jennings V, Pincetl S et al. (2011) Coupling biogeochemical cycles in urban environments: ecosystem services, green solutions, and misconceptions. Frontiers in Ecology and the Environment 9: 27-36

Peters MA, Hamilton D, Eames C (2015) Action on the ground: a review of community environmental groups' restoration objectives, activities and partnerships in New Zealand. New Zealand Journal of Ecology 39: 179-189

Pickett STA, Cadenasso ML, Grove JM, Groffman PM, Band LE, Boone CG et al. (2008) Beyond urban legends: an emerging framework of urban ecology, as illustrated by the Baltimore Ecosystem Study. BioScience 58: 139-150

Pickett STA, Cadenasso ML, Grove JM, Boone CG, Groffman PM, Irwin E et al. (2011) Urban ecological systems: scientific foundations and a decade of progress. Journal of Environmental Management 92: 331-362

Pulliam R (1988) Sources, sinks, and population regulation. The American Naturalist 132: 652-661

Ramalho CE, Hobbs RJ (2012) Time for a change: dynamic urban ecology. Trends in Ecology and Evolution 27: 179-188

Robinson SL, Lundholm JT (2012) Ecosystem services provided by urban spontaneous vegetation. Urban Ecosystems 15: 545-557

Ruiz-Jean MC, Aide TM (2005) Restoration success: how is it being measured? Restoration Ecology 13: 569-577

Savard JL, Clergeau P, Mennechez G (2000) Biodiversity concepts and urban ecosystems. Landscape and Urban Planning 48: 131-142

Sayer EJ (2006) Using experimental manipulation to assess the roles of leaf litter in the functioning of forest ecosystems. Biological Reviews 81: 1-31

Schwartz A, Muratet A, Simon L, Julliard R (2013) Local and management variables outweigh landscape effects in enhancing the diversity of different taxa in a big metropolis. Biological Conservation 157: 285-292 
Schwartz MW (1999) Choosing the appropriate scale of reserves for conservation. Annual Review of Ecological Systems 30: 83-108

Shochat E, Warren PS, Faeth SH, Mclntyre NE, Hope D (2006) From patterns to emerging processes in mechanistic urban ecology. Trends in Ecology and Evolution 21: 186-191

Sommer R, Learey F, Summit J, Tirrell M (1994) Social benefits of resident involvement in tree planting: comparison with developer-planted trees. Journal of Arboriculture 20: 323-328

Small EC, Sadler JP, Telfer MG (2003) Carabid beetle assemblages on urban derelict sites in Birmingham, UK. Journal of Insect Conservation 6: 233-246

Stewart GH, Ignatieva ME, Meurk CD, Earl RD (2004) The re-emergence of indigenous forest in an urban environment, Christchurch, New Zealand. Urban Forestry and Urban Greening 2: 149-158

Sullivan JJ, Meurk C, Whaley KJ, Simcock R (2009) Restoring native ecosystems in urban Auckland: urban soils, isolation, and weeds as impediments to forest establishment. New Zealand Journal of Ecology 33: 60-71

Svendsen ES, Campbell L (2008) Urban ecological stewardship: understanding the structure, function and network of community-based land management. Cities and the Environment 1: 1-31

Theobald EJ, Ettinger AK, Burgess HK, DeBey LB, Schmidt NR, Froelich HE et al. (2015) Global change and local solutions: tapping the unrealized potential of citizen science for biodiversity research. Biological Conservation 181: 236-244

Tilman D (1996) Biodiversity: population versus ecosystem stability. Ecology 77: 350-363

Torres-Camacho KA, Meléndez-Ackerman EJ, Díaz E, Correa N, Vila-Ruiz C, OliveroLora $S$ et al. (2017) Intrinsic and extrinsic drivers of yard vegetation in urban residential areas: implications for conservation planning. Urban Ecosystems 20: $403-413$

Tratalos J, Fuller RA, Warren PH, Davies RG, Gaston KJ (2007) Urban form, biodiversity potential and ecosystem services. Landscape and Urban Planning 83: 308-317 
Turner MG (1989) Landscape ecology: the effect of pattern on process. Annual Review of Ecological Systems 20: 171-197

Tzoulas K, Korpela K, Venn S, Yli-Pelkonen V, Kazmierczak A, Niemela J, James P (2007) Promoting ecosystem and human health in urban areas using Green Infrastructure: a literature review. Landscape and Urban Planning 81: 167178

Viles RL, Rosier DJ (2001) How to use roads in the creation of greenways: case studies in three New Zealand landscapes. Landscape and Urban Planning 55: $15-27$

Walmsley A (2006) Greenways: multiplying and diversifying in the $21^{\text {st }}$ century. Landscape and Urban Planning 76: 252-290

Westphal LM (2003) Social aspects of urban forestry: urban greening and social benefits: a study of empowerment outcomes. Journal of Arboriculture 29: 137-147

Williams NM, Winfree R (2013) Local habitat characteristics but not landscape urbanization drive pollinator visitation and native plant pollination in forest remnants. Biological Conservation 160: 10-18

Wortley L, Hero J, Howes M (2013) Evaluating ecological restoration success: a review of the literature. Restoration Ecology 21: 537-543

Wu J (2008) Making the case for landscape ecology: an effective approach to urban sustainability. Landscape Journal 27: 41-50

Young A, Mitchell N (1994) Microclimate and vegetation edge effects in a fragmented podocarp-broadleaf forest in New Zealand. Biological Conservation 67: 63-72

Young T (2000) Restoration ecology and conservation biology. Biological Conservation 92: 73-83 


\section{APPENDIX I:}

Location of study sites across Wellington

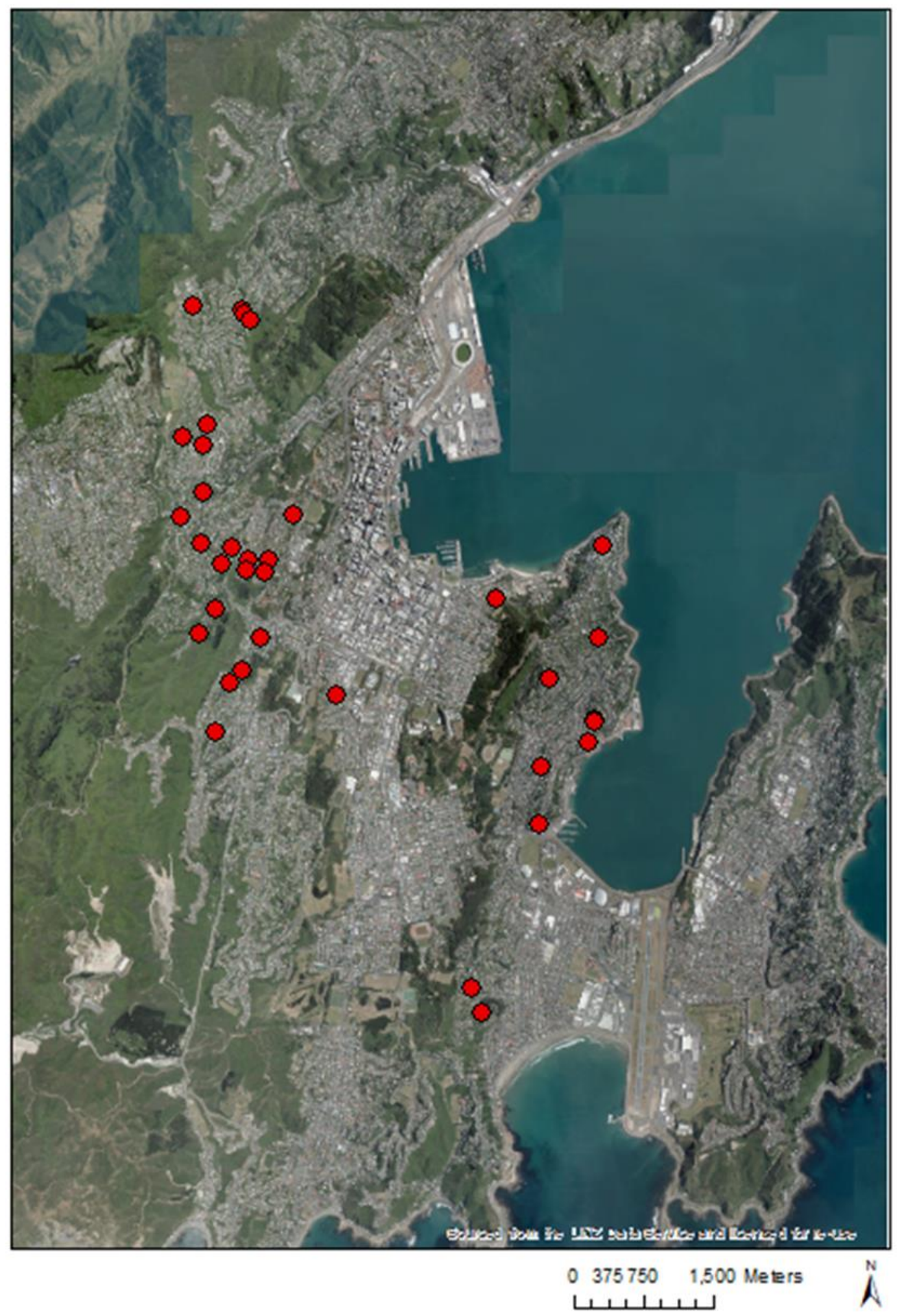

